$1-1-1928$

\title{
The Inheritance of Rachilla Length and its Relation to Other Characters in a Cross Between Avena Sativa and Avena Sativa Orientalis
}

T.E. Odland

Follow this and additional works at: https://researchrepository.wvu.edu/ wv_agricultural_and_forestry_experiment_station_bulletins

\section{Digital Commons Citation}

Odland, T. E., "The Inheritance of Rachilla Length and its Relation to Other Characters in a Cross Between Avena Sativa and Avena Sativa Orientalis" (1928). West Virginia Agricultural and Forestry Experiment Station Bulletins. 219.

https://researchrepository.wvu.edu/wv_agricultural_and_forestry_experiment_station_bulletins/219 @ WVU. It has been accepted for inclusion in West Virginia Agricultural and Forestry Experiment Station Bulletins by an authorized administrator of The Research Repository @ WVU. For more information, please contact ian.harmon@mail.wvu.edu. 
West Virginia University Libraries 


\section{Restricted}

Circulation Only

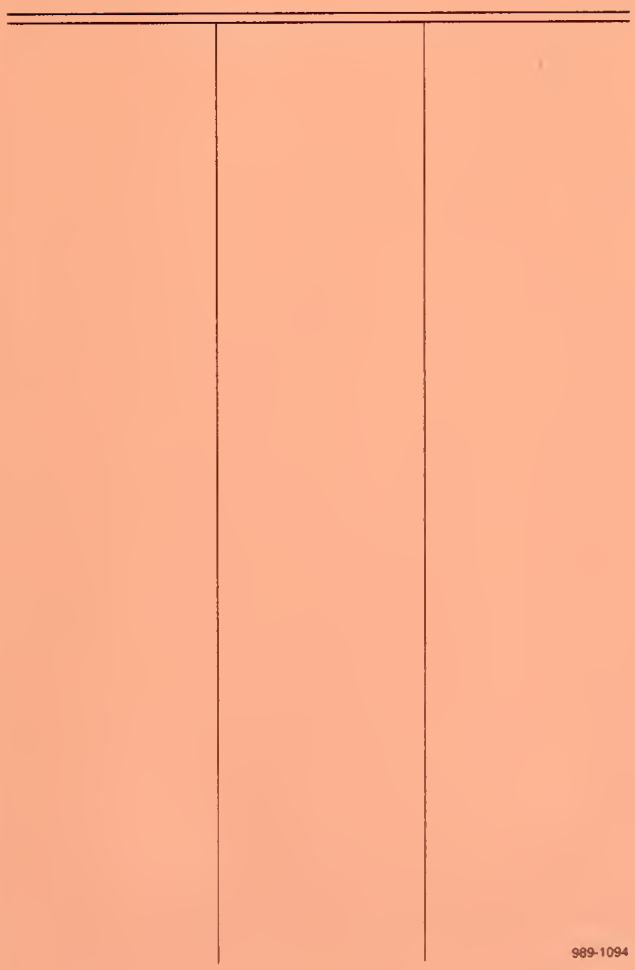





\title{
Aquricultural Experiment Station
}

College of Agriculture, ratest Birginia Rnibersity

\author{
N. J. GIDDINGS, Acting Director \\ Morgantown
}

The Inheritance of Racbilla Length and Its Relation to Other Characters in a Cross Between Avena

\section{Sativa and Avena Sativa Orientalis}

(Technical)

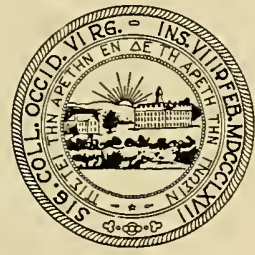

By

T. E. ODLAND

Publications of this Station will be mailed free to any citizen of West Virginia upon ten application. Address Director of the West Virginia Agricultural Experiment Sta. i. Morgantown, West Virginia. 


\section{AGRICULTURAL EXPERIMENT STATION STAFF}

FRANK BUTLER TROTTER, A. M., LL. D............ President of the Unive

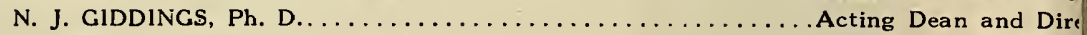

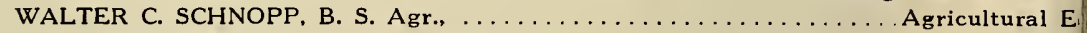
JOHN C. JOHNSTON

\section{AGRONOMY AND GENETICS}

R. J. Garber, Ph. D. Agronomist and Geneticist

E. P. Deatrick, Ph. D. Associate Agronomist (Solls)

T. E. Odland, Ph. D.

Associate Agronomist

T. C. Mcllvaine, Ph. D. $\dagger$

Assistant Agronomist (Soils)

D. R. Dodd, M. S.

Assistant Agronomist

M. M. Hoover, M. S.

Junior Agronomist

H. K. Rowley, M. S. Agr.**

Seed Analyst

\section{ANIMAL HUSBANDRY}

E. A. Livesay, M. S.

Animal Husbandman

Chas. V. Wilson, M. S.

Assistant Animal Husbandman

J. H. Longwell, M. A.,

Assistant Animal Husbandman

J. H. Rietz, D. V. M.

Associate Veterinarian

R. H. Tuckwiller, B. S. Agr.*

Assistant Animal Husbandman

\section{CHEMISTRY}

R. B. Dustman, Ph. D.

Associate Chemist

Chas. E. Weakley, Jr., B. A.

Assistant Chemis

L. P. Hansen, Ph. D.

T. B. Leith, B. A.** Assistant Chemist

Leland Shriver

Assistant in Chemistry

\section{DAIRY HUSBANDRY}

E. L. Anthony, M. S. Agr.

Dairy Husbandman

H. O. Henderson, M. S. Agr.

Associate Dairy Husbandman

G. Malcolm Trout. M. S.

Assistant Dairy Husbandman

\section{ENTOMOLOGY}

L. M. Peairs, Ph. D.

Entomologist

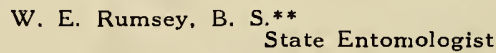

L. E. Dills, M. S.**

Assistant in Entomology

\section{FARM ECONOMICS}

A. J. Dadisman, Ph. D. Farm Econc

Paul A. Eke, Ph. D.

Assistant Farm Econc

F. D. Cornell, Jr., M. S.

Junior Farm Mechan

W. W. Armentrout, M. S.

Junior Farm Econc

HOME ECONOMICS

Rachel H. Colwell, A. M.

Home Econd

Hazel C. Cameron, M. S.

Research Specialist in $F$

Nell Nesbitt, A. M.

Research Specialist in Home

HORTICULTURE

H. E. Knowlton, Ph. D.

Associate Horticul

H. L. Crane, M. S. Agr. Associate Horticult

K. C. Westover, M. S. Agr. Assistant Horticult

L. F. Sutton, B. S. Agr. Assistant Horticul

H. P. Sevy, M. S. Agr. Assistant in Horticl

M. B. Hoffman, M. S. Assistant in Horticl

\section{PLANT PATHOLOGY}

N. J. Giddings, Ph. D. Plant Patho Anthony Berg, M. S. Associate Plant Patho

L. H. Leonian, Ph. D Associate Plant Patho

E. C. Sherwood, M. S. Assistant Plant Patho

\section{POULTRY HUSBANDRY}

Horace Atwood, M. S. Agr. Poultry Husbar

E. T. Wightman, M. S. Agr. Junior Poultry Husban

\section{RURAL SOCIOLOGY}

T. L. Harris, Ph. D.

Rural Socicir

\section{ZOOLOGY}

F. E. Chidester, Ph. D.

Zoc

* In cooperation with the U. S. Department of Agriculture, Washington, D. C. tn charge of the Lakin Sub-Station, Lakin, W. Va.

**In cooperation with the State Department of Agriculture, Charleston, W. Va fln charge of the Reymann Memorial Farms, Wardensville, W. Va. 


\section{CONTENTS}

iVIEW OF LITERATURE ........................... 5

ITERIALS AND METHODS ...................... 7

TERMINATION OF SIZE OF SAMPLE $\ldots \ldots \ldots \ldots \ldots \ldots \ldots \ldots \ldots$

TERMINING SIZE OF Fs FAMILIES $\ldots \ldots \ldots \ldots \ldots \ldots \ldots \ldots \ldots$

FECT OF SOIL PRODUCTIVITY ON LENGTH OF RACHILLA ....... I 2

HERITANCE OF LENGTH OF RACHILLA .................13

AEEDING BEHAVIOR OF $F_{3}$ PROGENIES FOR LENGTH OF RACHILLA . . 17 RRELATION BETWEEN $F_{2}$ PLANTS AND THEIR $F_{3}$ PROGENIES $\ldots \ldots 18$ RIABILITY IN $F_{3}$ PROGENIES . . . . . . . . . . . . . . . . . . 19

HERITANCE OF OTHER CHARACTERS $\ldots \ldots \ldots \ldots \ldots \ldots \ldots 20$

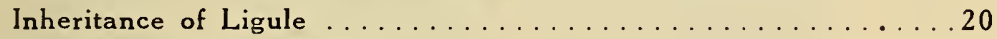

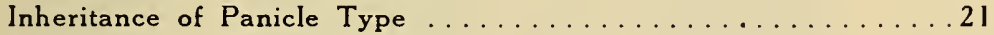

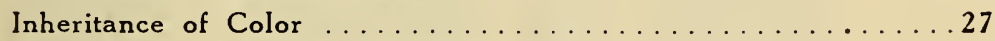

Inheritance of Rachilla Pubescence $\ldots \ldots \ldots \ldots \ldots \ldots \ldots 28$

IERRELATION OF CHARACTERS ................. 30

ERELATION OF RACHILLA LENGTH WITH THE OTHER CHARAC-

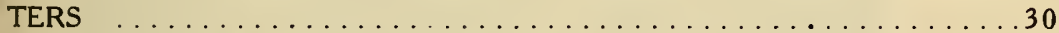

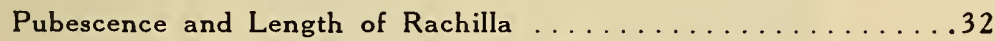

Ligule, Panicle Type, Color of Grain, and Length of Rachilla . . ..34

IMMARY . . . . . . . . . . . . . . . . . . . . . . . . . 36

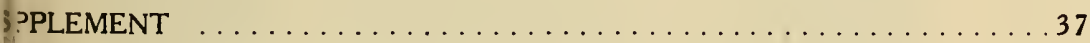

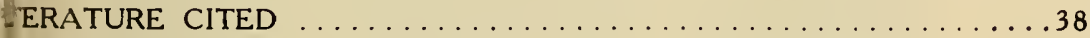

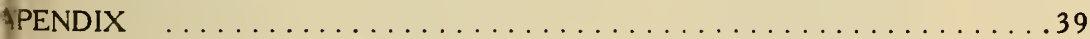




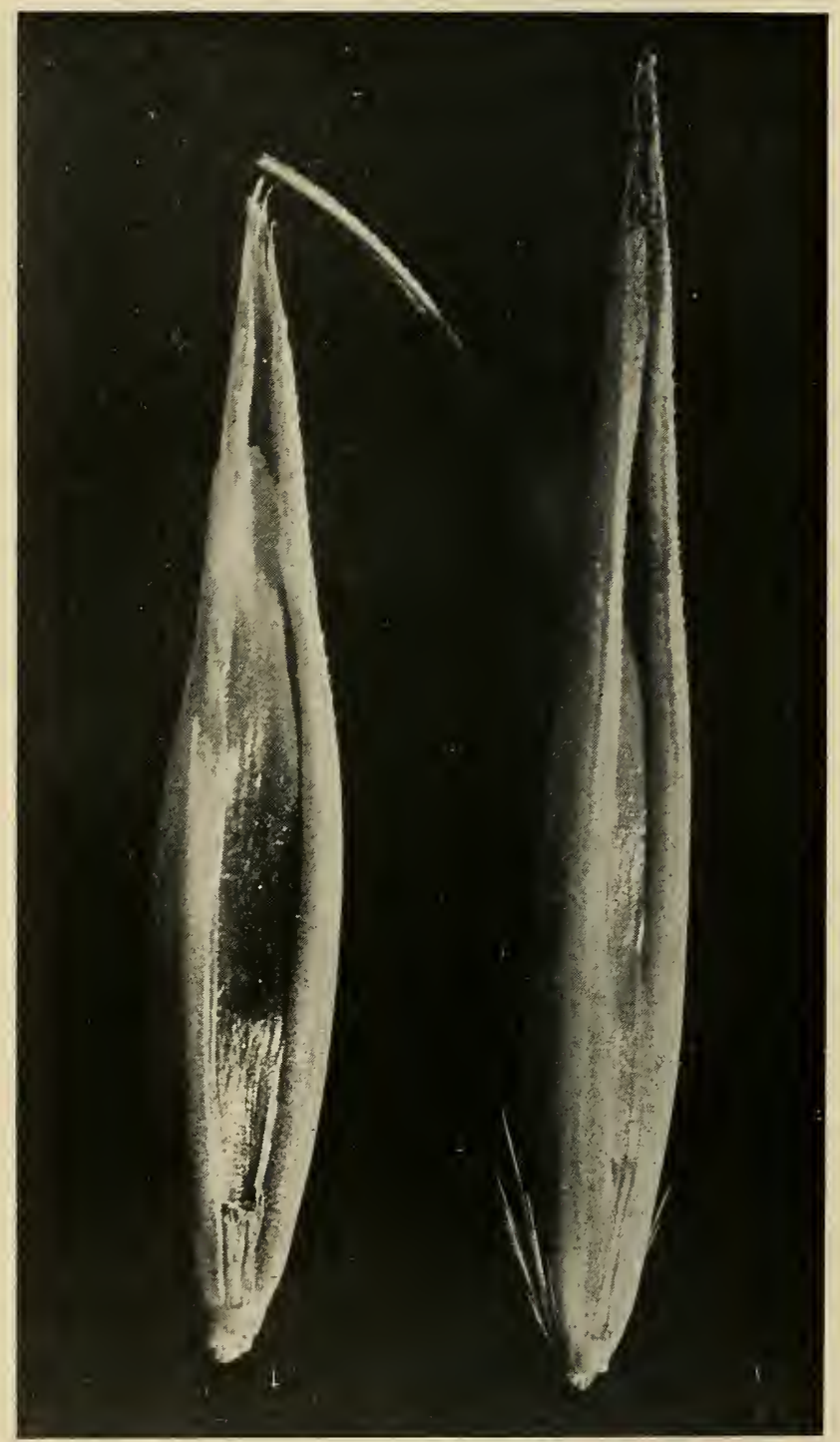

Fig. 1.-Grain types of the parental varieties. Garton 784 on left and Early Gothland on right. 


\section{The Inheritance of Rachilla Length and Its Relation}

\section{to Other Characters in a Cross Between Avena}

\section{Sativa and Avena Sativa Orientalis}

The inheritance of quantitative characters such as yield, size of int, and others of like nature has been much less extensively studied In the inheritance of qualitative characters. The reason is found gely in the fact that they are usually much less easily analyzed and en present rather complex problems. Quantitative characters are en so influenced by environmental conditions that genetic differes are obscured. A number of workers have, however, demonixted that the inheritance of size characters may be explained on a torial basis similar to that of the inheritance of qualitative charers. Sax (16), Lindstrom (9) and others have pointed out the lirability of attempting to correlate size characters with easily rechized qualitative characters and thus facilitate the analysis of the imer in any inheritance study.

A quantitative character that is relatively stable under varying rironmental conditions is obviously very desirable for making a Idy of the nature of size inheritance. In the present study the size lracter chosen, length of rachilla in oats, seemed to offer an excepi ally stable character and one that could be studied in relation to a inber of definite qualitative characters.

\section{REVIEW OF LITERATURE}

East (2) made a study of the inheritance of corolla length in a acco cross. This study is taken as typical of many size inheritance dies made by East. In this tobacco cross the corolla length in the generation was intermediate between the two parents and was only htly more variable than the more variable parent. The $F_{2}$ generai) ranged between the two parents and had a much greater variaty than either the parents or the $F_{1}$ generation. In the $F_{3}$ and iceeding generations families were recovered with various lengths corolla. Some of these families showed a variability no greater in that of the parents, while others were more like the $F_{2}$ in this esect. The data indicate that the inheritance of this character can

*Presented to the faculty of the Graduate School of Cornell University, Ithaca, N. Y., 1926 , as a major thesis in partial fulfilment of the requirements for the degree of or of Philosophy. Submitted for publication as a Station Bulletin, October, 1926.

Acknowledgement is due to Dr. H. H. Love, of Cornell University, for his helpful :tion and guidance during the course of this investigation, and to Dr. R. J. Garber, of $t$ Virginia University, who contributed many valuable suggestions with respect to out$\mathrm{g}$ the problem and handling the data. 
be explained on a multiple factor basis. In this paper East outli: certain requirements which, if met in a size inheritance study, tend indicate that the results may be explained on a factorial basis.

Quisenberry (15) in a study of the inheritance of length of gr in an oat cross found the $F_{1}$ to have grains intermediate in length wh the $F_{2}$ ranged from one parent to the other. In $150 F_{3}$ families, $t$ were recovered with a mean length as short as the short parent a four with a length as great as the long parent. Between the extren were lines that apparently bred true for intermediate lengths. results were explained on the basis that the parents differed by least three main factors or groups of factors for grain length.

Garber and Quisenberry (6) studied the inheritance of date heading, leaf width, number of culms, and color of seed in anoti oat cross. Earliness was found to be inherited as a dominant charac with evidence of a two factor difference. Leaf width was found to a variable character. One $F_{3}$ family was recovered with a leaf wic less than the narrow-leaved parent. The data indicated that this ch acter was controlled by multiple factors. The number of culms $\mathrm{v}$ also found to be greatly influenced by environment, but the data dicated that it was an inherited character. Seed color was found be due to a single factor difference. No evidence of linkage found between any of the characters studied.

Noll (14), in a study of the inheritance of earliness in crosses tween early and late varieties of oats, found the $F_{1}$ generation to as early or earlier than the early parent. The $F_{2}$ ranged beyond extremes of both parents. Homozygous races were obtained in $F_{3}$ a $\mathrm{F}_{4}$ which covered the same range as the $\mathrm{F}_{2}$. Earliness was apparen due to a series of dominant factors, which together had a cumulat effect. The data, the author states, indicate but do not prove clusively that the factors had the same effect.

Caporn (1) crossed an early with a late variety of oats. T lines out of $106 \mathrm{~F}_{3}$ families were found to be as early as the ea parent but no lines were recovered that were as late as the late pare The author explains the results obtained on a three factor basis. L ripening was found to be closely associated with the amount tillering.

Nilsson-Ehle (12) made a study of various size characters. Th studies have been reviewed by Hayes and Garber (8). Transgress segregation was found in oat crosses involving differences in hei€ leaf width, kernel size, and number of florets per spikelet. The sults were explained on a multiple factor hypothesis. Nilsson-Ehle a 
tained transgressive segregation for date of maturity in certain oat c)sses. Homozygous forms were obtained in the $F_{3}$ progenies which re earlier than the early parent and also some that were later than late parent.

The linkage of size factors with certain qualitative characters tre been noted by several workers. Tedin and Tedin (18) crossed awo-rowed hulled with a six-rowed hull-less barley. The two-rowed rley was about ten centimeters higher than the other variety. The ineritance of type of spike and of the hull condition was explained single factor differences which were independent of each other. Eidence for linkage between the factor for two-rowedness and a tor for plant height was found. The authors state that evidence s also found that heterozygosity in the factor for two-rowedness a marked "stimulating" effect upon height of plant.

Sax (16) studied the relation between size of seed and pigmention of seed in beans. A linkage was found between factors, or g)ups of factors, for seed weight and factors for pigmentation and tern of the seed coat.

Lindstrom (9) in a study of inheritance of size of tomatoes find that a factor for size of fruit was linked with a factor for skin or.

Griffe ( $y$ ) using barley, studied the relation of resistance to Flminthosporium sativum and certain morphological characters. concluded that resistance to this disease was controlled by at least lee factors or groups of factors apparently linked with the factors ermining the character pairs: six-rowed versus two-rowed; black sus white glumes, and rough versus smooth awn. The linkage was complete as resistance or susceptibility could be combined with desired morphological character.

\section{MATERIALS AND METHODS}

The object of the study reported in this bulletin was to attempt cletermine the mode of inheritance of a definite size character, length rachilla in oats, and its relation to certain other qualitative charac-

The material for this study was obtained by making a cross ween Early Gothland (Avena sativa) and Garton 784 (Avena (iva orientalis).

The Early Gothland parent has a pubescent rachilla approxirtely 2.7 millimeters long on its lower grain (Fig. 1), while in the iton 784 parent the rachilla is extremely short, being only approxirely 1.6 millimeters long. It is free from pubescence except for an rasional hair. 
Early Gothland is a white grained variety, has an open type panicle (Fig. 2), and has a leaf with a very prominent ligule. Garton 784 parent has black colored grains, has a side type of pani and has no ligule at the juncture of the leaf blade and the leaf she: The parental material used all descended from a single panicle of $e$ variety selected from pure line material grown in the Plant Breed Nursery at Morgantown, West Virginia, in 1921. The reciprc crosses were made in 1922.

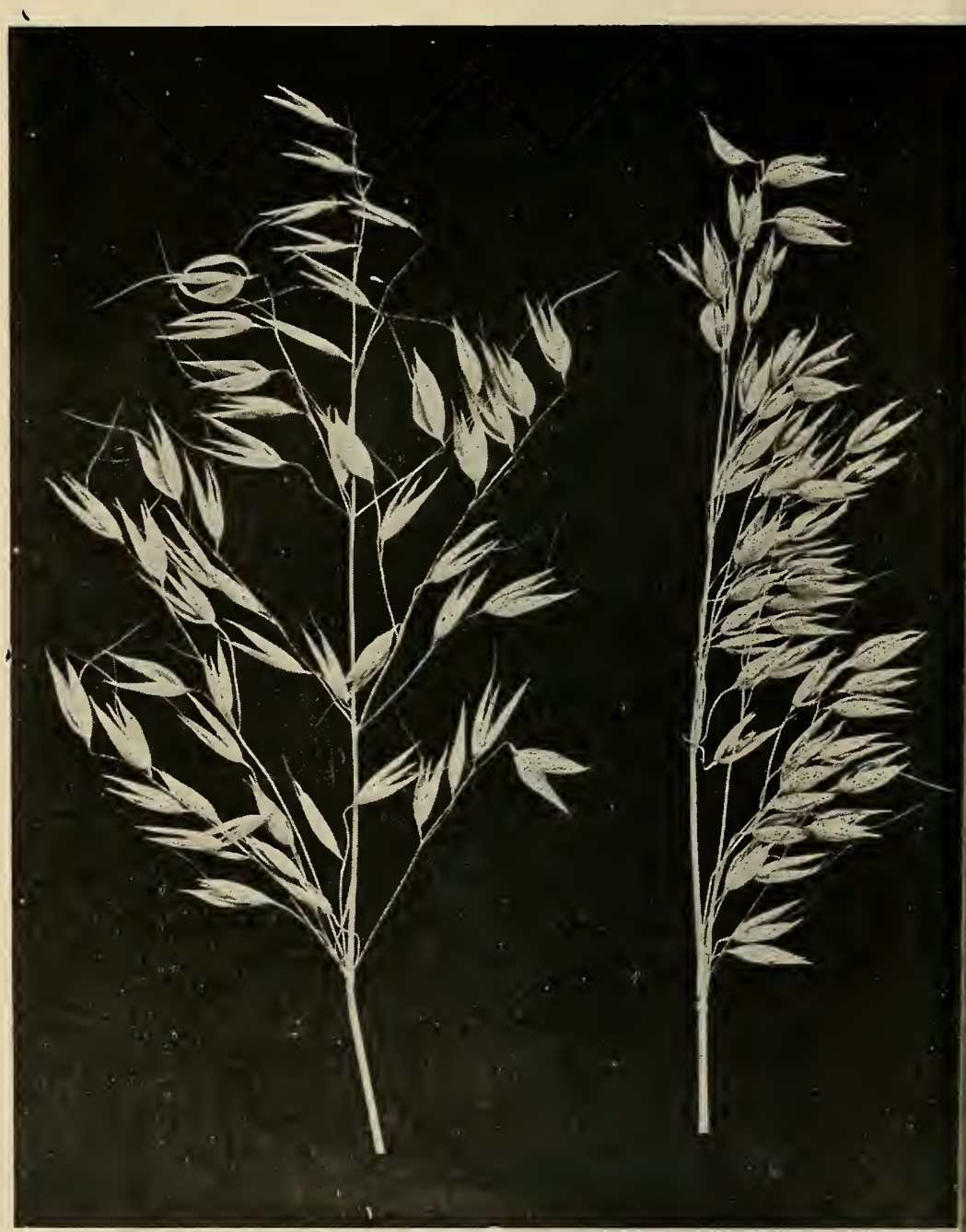

Figure 2.-Panicle types of the parental varieties. Early Gothland on left and C 784 on right. 
An $F_{1}$ generation was grown in the greenhouse during the winter 2-23. The plants were late in maturing so that only enough ds were secured to grow an $F_{2}$ population of 290 plants in 1923. few additional $F_{1}$ plants and also parental material were grown $h$ the $F_{2}$ generation in the field. Larger $F_{2}$ populations were grown 924 and 1925. A few $F_{1}$ plants and also parental material were iwn with these each year. In $1925 \mathrm{~F}_{3}$ families were grown from a aber of the $F_{2}$ plants.

All material in this study was grown in rows five feet long and ced one foot apart. Twenty seeds were planted per row. At the of each row and set off by a small stake, three seeds of Victory were planted in order to eliminate border effect as far as possible. se plants were pulled and discarded before any of the plants under yy were harvested. When it was necessary to plant only a part of bw of the material under study on account of lack of seed, the ainder of the row was planted to Victory and the plants discarded he same manner as the border plants.

The $F_{3}$ families from which it was planned to get rachilla measments were all planted in five-row plots except in a few instances re there was not enough seed. Rachilla measurements were made 60 such $F_{3}$ families. In addition to these, 75 families consisting of one row each were grown in order to get additional data on the tion of the ligule and panicle type. The five-row $F_{3}$ families were from $F_{2}$ plants grown in 1924 while the single row families were n both the 1923 and $1924 \mathrm{~F}_{2}$ plants. The parental material in 5 was grown in 18 three-row plots distributed among the $F_{2}$ and $\mathrm{F}_{3}$ families. Both parents appeared at distances of from 23 to 36 s apart. The average distance apart of the parental material was rows.

A plot of each variety was also grown on rich and poor soil in 3 for the purpose of studying the influence of the productivity of soil on the length of the rachilla.

The rachilla measurements were made by means of a pair of portional dividers (Fig. 3) using a ratio of 10 to 1 and reading measurements on a millimeter scale. The units in which the measnents are reported are in terms of .1 millimeters. A mounted readglass was used to facilitate making the readings obtained with the ders.

The classification of the panicle type and the ligule note were e in the field before the plants were harvsted. The classifications color of grain and for rachilla pubescence were made at the time the rachilla was measured. 


\section{DETERMINATION OF SIZE OF SAMPLE}

Before proceeding with the measuring of the $F_{2}$ material it necessary to make measurements of the rachillas of the parental $r$ terial in order to determine how many grains would be necessary a dependable sample from each plant. Preliminary measureme made in 1922 had shown that the length of rachilla did not $v$ significantly on grains taken from the base to tip on the same pani nor on grains from different panicles of the same plant. The lead panicle was therefore chosen to represent each plant measured. grains selected from this panicle were taken in a systematic order $\mathrm{fr}$ the tip to the base of the panicle..

The preliminary measurements also indicated that the sh rachilla parent was probably the more variable as measured by coefficient of variability. This parent was therefore chosen for mak a determination on the size of sample required to represent a ple For this study 15 grains were taken in systematic order from tip base of the leading panicle from 100 Garton 784 plants grown in 19 Samples consisting of three, five, and eight grains from each pan: were then made up from the original 15-grain samples. Freque, distributions were then made of the means as secured by these differ samples. The statistical constants obtained are shown in Table 1.

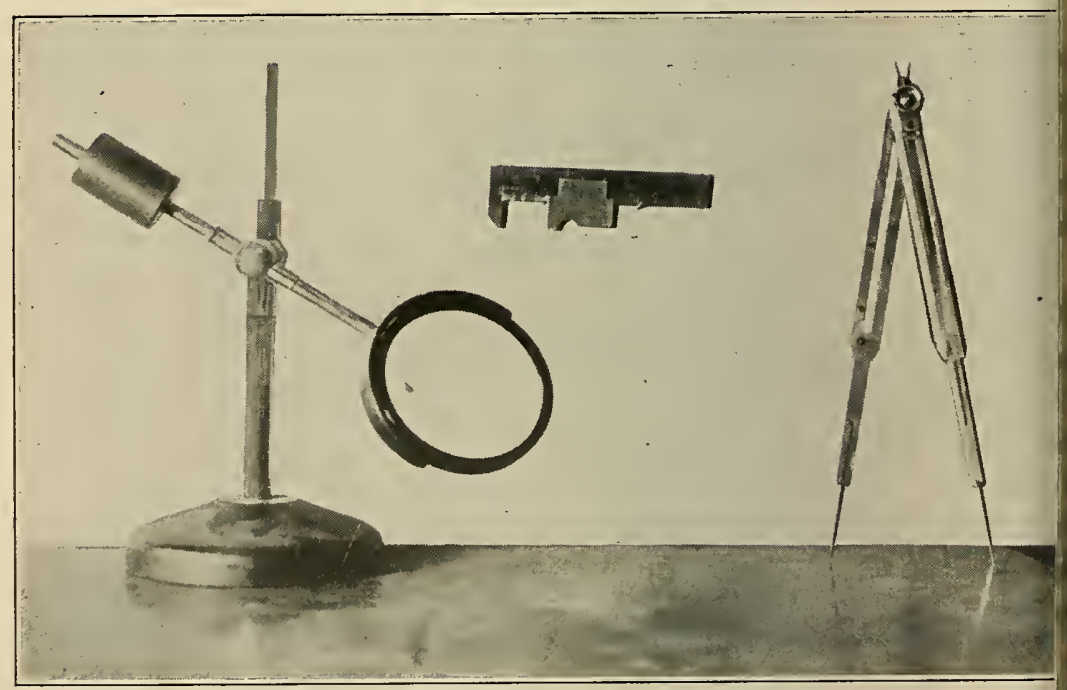

Fig. 3.-Equipment used in making rachilla measurements. 
3LE 1.-Statistical constants for length of rachilla for samples of 3, 5, 8, and 15 grains obtained from 100 plants of the Garton 784 parent grown in 1923.

\begin{tabular}{|c|c|c|c|c|c|}
\hline 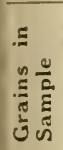 & 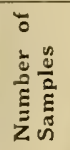 & $\underset{\text { Units }}{\text { Means in }} .1 \mathrm{~mm}$. & $\begin{array}{l}\text { Standard } \\
\text { Deviation }\end{array}$ & $\begin{array}{c}\text { Coefficient } \\
\text { of } \\
\text { Variability }\end{array}$ & $E_{s}$ \\
\hline 3 & 100 & $16.570 \pm 0.070$ & $1.042 \pm 0.050$ & $6.29 \pm 0.30$ & 0.703 \\
\hline 5 & 100 & $16.630 \pm 0.065$ & $0.966 \pm 0.046$ & $5.81 \pm 0.28$ & 0.652 \\
\hline 8 & 100 & $16.570 \pm 0.057$ & $0.852 \pm 0.040$ & $5.14 \pm 0.24$ & 0.575 \\
\hline 15 & 100 & $16.510 \pm 0.054$ & $0.806 \pm 0.038$ & $4.88 \pm 0.23$ & 0.544 \\
\hline
\end{tabular}

The data of Table 1 show that there is no significant difference he means for length of rachilla, whether three, five, eight, or fifgrains were selected as a representative sample. The standard iation and the coefficient of variability are reduced as the size of ple is increased. It was decided to use a sample of five grains n each plant as a representative sample for determining the length achilla.

\section{DETERMINING THE SIZE OF $\boldsymbol{F}_{3}$ FAMILIES}

The question also arose as to how many plants it would be necry to grow in order to obtain a dependable estimate of the breedbehavior for the length of rachilla in any particular family in the ind later generations. This question was of considerable import$\Rightarrow$ in this study on account of the amount of time it required to i:e the measurements.

For this study the $F_{2}$ population grown in 1923 was used. The $\mathrm{F}_{2}$ plants were first divided into 10 samples of 29 plants each by cting plants $1,29,58$, and so on, for sample number one, plants 0,59 , and so on, for sample number two, and proceeding in the e way for the other eight samples. In a similar way six samples 8 plants each, five samples of 58 plants, and three samples of 96 its were made up. Statistical constants were then calculated for 1 of these samples. These constants are given in Table 19 of the endix. In Table 2 a summary is given of the results obtained.

Since the coefficient of variability is the constant which is freitly used to determine if any $\mathrm{F}_{3}$ family is homozygous for any in set of size factors, a comparison of this constant in the various ples will give an indication of the number of individuals which 
TABLE 2.-Range in means and in coefficients of variability for lengt rachilla when samples of $29,48,58$, and 96 plants were taken fron $F_{2}$ generation grown in 1923.

\begin{tabular}{|c|c|c|c|c|c|}
\hline \multirow{2}{*}{ 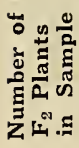 } & \multirow{2}{*}{ 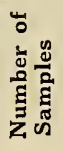 } & \multicolumn{2}{|c|}{ Range in Means } & \multicolumn{2}{|c|}{ Range in Coefficients of Varia } \\
\hline & & High & Low & High & Low \\
\hline 29 & 10 & $22.172 \pm 0.289$ & $21.207 \pm 0.295$ & $12.29 \pm 1.10$ & $8.00 \pm$ \\
\hline 48 & 6 & $21.917 \pm 0.214$ & $20.937 \pm 0.215$ & $11.27 \pm 0.79$ & $8.91 \pm$ \\
\hline 58 & 5 & $21.690 \pm 0.211$ & $21.362 \pm 0.174$ & $11.24 \pm 0.71$ & $9.19 \pm$ \\
\hline 96 & 3 & $21.875 \pm 0.161$ & $21.000 \pm 0.142$ & $10.66 \pm 0.53$ & $9.48 \pm$ \\
\hline 290 & 1 & \multicolumn{2}{|c|}{$21.652 \pm 0.083$} & \multicolumn{2}{|c|}{$9.65 \pm 0.27$} \\
\hline
\end{tabular}

will be required to give a trustworthy sample of the $F_{2}$ generat Since no $F_{3}$ families with a variability greater than that of the $F_{2}$ ordinarily expected in any cross of this kind involving size fact any sample that is found satisfactory as a representative of the population should be large enough to be taken as a trustworthy san of any of the $F_{3}$ and later progenies grown.

Table 2 shows the coefficient of variability ranges from $8 . C$ 0.71 to $12.29 \pm 1.10$ when samples of only 29 individuals were ta: The wide range in this constant indicates that this would not $k$ sample large enough to fairly represent the entire $F_{2}$ populat When 48 plants were used the coefficient ranges from $8.91 \pm 0.6$ $11.27 \pm 0.79$. The coefficient of variability for the entire popula is $9.65 \pm 0.27$. As the number of individuals in the samples is creased to 58 and 96 respectively the range between the high and coefficients becomes less. From these data it would seem that al 50 individuals in the $F_{3}$ families could be accepted as being a tr worthy sample. On account of the other characters studied in . nection with the size character it was decided to plant 100 seeds each $F_{3}$ family where enough seed was available but to measure , a random sample of 50 plants taken from each family.

\section{EFFECT OF SOIL PRODUCTIVITY ON LENGTH OF RACHII}

In order to study the effect of the productivity of the soil on length of rachilla a plot of each parent was planted on both rich poor soil. The rich soil plots were located on land that had at time been used for gardening purposes and which had received he applications of fertilizers and manure. The plots located on the $\mathrm{F}$ 
1 were located on a ridge where the soil was in a very low state of i) ductivity. The plots consisted of 15 five-foot rows each.

The heights of all plants were taken before harvest. Each plant as harvested and threshed separately. The grains for measuring ire removed from the leading panicle before threshing. One hunlid plants taken in order from each plot were used for rachilla igth determinations. In tabulating the data obtained, only the lds and heights from the plants on which rachilla measurements re made have been used. A summary of the results obtained is en in Table 3.

BLE 3.-Means for length of rachilla, yield, and height of individual plants of Early Gothland and Garton 784 parents grown on rich and poor soil in 1923.

\begin{tabular}{|c|c|c|c|c|c|}
\hline Parent & 离 & 章搃 & $\begin{array}{l}\text { Average Length of } \\
\text { Rachilla in .1 } \\
\text { mm. Units }\end{array}$ & $\begin{array}{c}\text { Average } \\
\text { in } \\
\text { Grams }\end{array}$ & $\begin{array}{l}\text { Height in Cen- } \\
\text { timeters }\end{array}$ \\
\hline E.ly Gothland & 100 & Rich & $27.720 \pm 0.067$ & $6.95 \pm 0.25$ & $114.70 \pm 0.55$ \\
\hline E:ly Gothland & 100 & Poor & $25.850 \pm 0.076$ & $2.69 \pm 0.10$ & $76.05 \pm 0.52$ \\
\hline Crton 784 & 100 & Rich & $16.710 \pm 0.055$ & $\overline{6.32 \pm 0.21}$ & $105.15 \pm 0.62$ \\
\hline Crton 784 & 100 & Poor & $16.120 \pm 0.053$ & $3.87 \pm 0.14$ & $80.35 \pm 0.49$ \\
\hline
\end{tabular}

It is clearly evident from the results shown in Table 3 that there was a considerable difference in the productivity of the soil between two plots both as measured by yield and by the height of the nts. The difference between the two plots of Garton 784 was atively less in both instances than between the plots of Early Gothd.

It is also evident that the productivity of the soil has influenced length of rachilla in both parents. In the Early Gothland parent difference between the length of rachilla in the rich and poor soil ts amounts to $1.870 \pm 0.101$ units and in Garton 784 it is $0.590 \pm$ 76 units. Even with soil differences as extreme as these were, the $d$ erences in rachilla length were not large. Evidently this character srery stable and only relatively little influenced by soil differences.

\section{INHERITANCE OF LENGTH OF RACHILLA}

The mode or inheritance of length of rachilla was studied by rking measurements of the hybrid material as described previously, cinputing statistical constants, and analyzing the data from a bio- 
metrical standpoint. In this cross no significant difference was for between the reciprocal crosses in the inheritance of length of rack or in any of the other characters studied. In the tabulations and of data presented the two crosses are, therefore, combined.

A summary of the results obtained in the three years for m, urements of the parental material, the $F_{1}$ plants, and the $F_{2}$ populati is given in Table 4 . The data show that the length of rachilla var only slightly in the different years both in the parents and in the populations. The means for the Early Gothland parent were 27.51 $0.060,26.608 \pm 0.054$, and $26.885 \pm 0.019$ units for the three $y$ 1923, 1924, and 1925, respectively. Between the years 1923 : 1924 there was a difference of $0.904 \pm 0.081$. This is a relativ small difference but significant in the light of its probable error. difference between the means of this parent for 1924 and 1925 $0.277 \pm 0.057$. The difference is about five times its probable er and indicates that there was less difference in seasonal influences tween 1924 and 1925 than between 1923 and 1924. When means for the years 1923 and 1925 are compared there is found to a difference of $0.629 \pm 0.063$. This difference may also be conside as significant.

The coefficients of variability for this parent were $5.52 \pm 0$. $5.69 \pm 0.14$, and $3.18 \pm 0.05$ for the three years, respectively. obvious that there was no difference in variability in this parent measured by the coefficient of variability between the years 1923 a 1924. The difference in this constant, however, between the $t$ years 1923 and $1925,2.34 \pm 0.16$, shows that this parent was /s variable in 1925 than in the other two years. As will be shown le this was also true of the Garton 784 parent.

The means for the Garton 784 parent were $16.731 \pm 0.0$ $16.119 \pm 0.034$, and $16.210 \pm 0.016$ for the three years, respective The difference in means for the years 1923 and 1924 was 0.61 : 0.052 units. This is not a large difference, but is significant in light of its probable error. The difference in means for this par between the years 1924 and 1925 was $0.091 \pm 0.037$, a differes less than three times its probable error and, therefore, not conside: significant. The difference in means for the years 1923 and 19 was $0.521 \pm 0.043$, which may be considered as a significant differen

The coefficients of variability for this parent for the three ye were $5.89 \pm 0.17,5.38 \pm 0.15$, and $4.37 \pm 0.07$, respectively. Betw the years 1923 and 1924 there was a difference of $0.51 \pm 0.23$. T difference is not significant in the light of its probable error a 


\begin{tabular}{c|c|c|c|c|c|}
$n$ & \pm & 0 & 0 & $n$ & 0 \\
0 & 0 & 0 & 0 & 0 & 0 \\
+1 & +1 & +1 & +1 & +1 & +1 \\
$\sim$ & $a$ & $\infty$ & 0 & $\infty$ & $n$ \\
in & 0 & - & $\infty$ & $m$ & $m$ \\
in & $n$ & $m$ & $n$ & $n$ & +
\end{tabular}

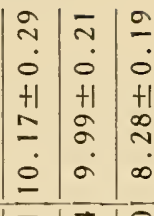

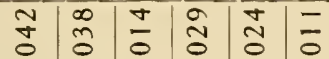

กั

\begin{tabular}{l|lllll}
$\dot{0}$ & 0 & 0 & 0 & $\dot{0}$ & $\dot{0}$
\end{tabular}

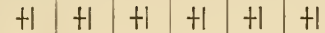

$0 \begin{array}{lllll}n & n & 0 & \infty & \infty \\ & \infty & 0 & 0\end{array}$

in in $\infty$ a

$-1-1000000$

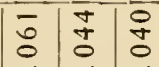

กี่

$\circ \dot{0} 0$

$+1+1+1$

$\frac{0}{1}+\frac{\pi}{4}$

$\frac{a}{n}$

-

$\dot{n}|\dot{n}|-$

$\sum_{\Sigma}^{\infty}$

○

0000000

$+1+1+1+n+1$

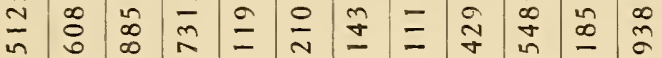

$\therefore \dot{0} \dot{0} \dot{0} \dot{0} \dot{0} \dot{0} \dot{0} \dot{0} \dot{0}$

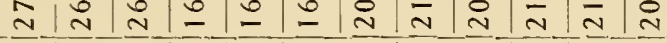

$.0 \mathrm{n}$

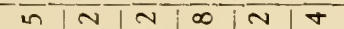

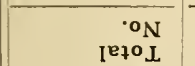

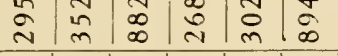

ले

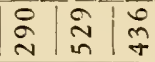

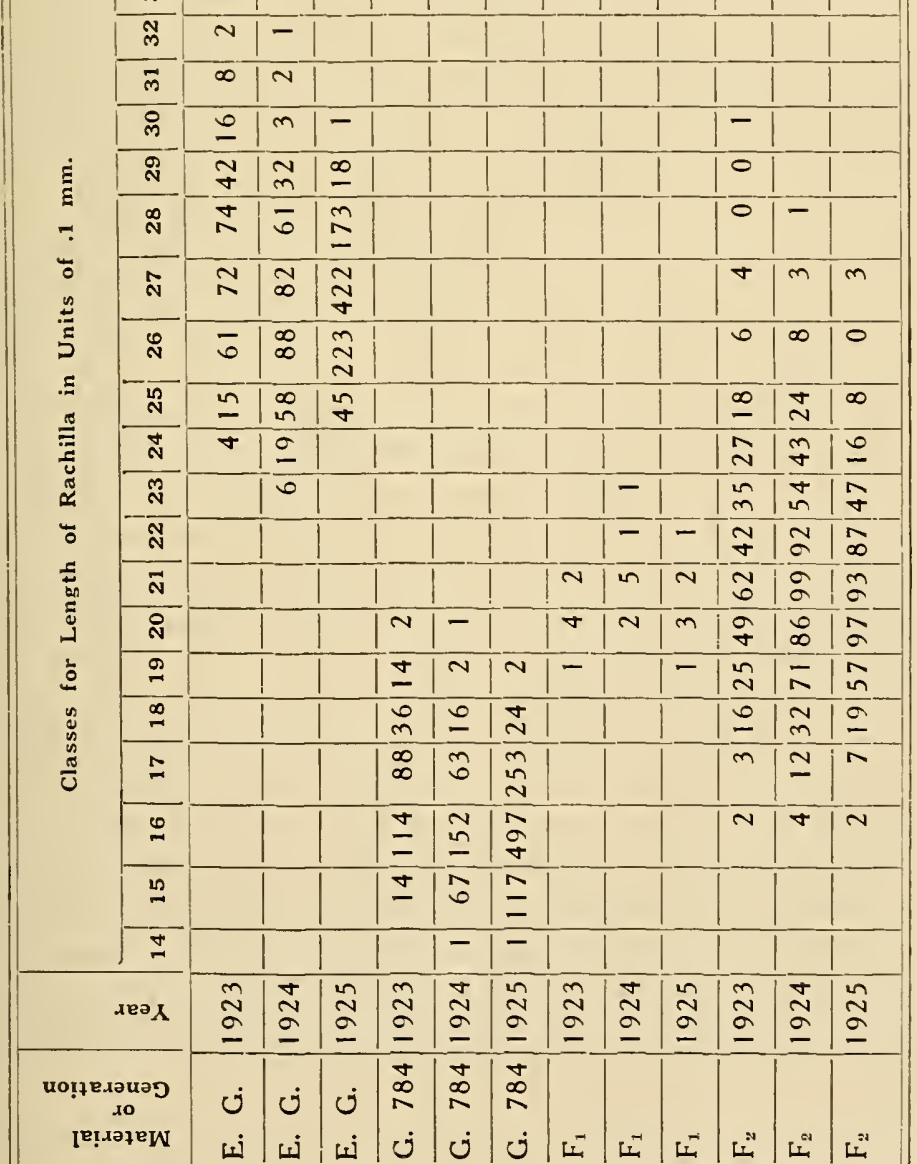


therefore, this parent is like the Early Gothland in that there was difference in variability in the first two years of the experiment. tween the years 1924 and 1925 there was a difference of $1.01 \pm 0$. which is sisnificant. The difference for this constant between years 1923 and 1925 was $1.52 \pm 0.18$, which may also be conside as an actual difference. Like the Early Gothland parent the Gar 784 parent showed less variability in 1925 than in the other years.

By means of the coefficient of variability the variability of two parents may be compared directly. These constants did differ significantly between the two parents in 1923 and $1924 \mathrm{bu}$ 1925 there was a difference of $1.19 \pm 0.09$. This shows that in latter year the Early Gothland parent was less variable than the oi parent.

The means for the $F_{2}$ populations were $21.548 \pm 0.087,21.18$ 0.062 , and $20.938 \pm 0.056$ units for the three years 1923,1924 , 1925, respectively. The difference in means between the years 1 and 1924 was $0.363 \pm 0.107$ and between the years 1923 and 1 it was $0.610 \pm 0.103$. The difference is approximately three times probable error in the former case and six times its probable erro the latter case and, therefore, both are considered significant. difference in means between the years 1924 and 1925 was 0.24 0.084 , a difference which is a little less than three times its prob: error. The $F_{2}$ population, therefore, is like the parents in that mean length of rachilla in the years 1924 and 1925 was slightly than in 1923.

An examination of Table 4 shows that in variability, as meast by the coefficient of variability, there was no difference in the generation for the character under study between the years 1923 1924. Between the years 1924 and 1925 there was a differenci $1.71 \pm 0.28$, which is significant. In respect to variability, theref the $F_{2}$ showed less range in 1925 than in the previous years and similar to the parents in this respect.

In all three years the $F_{1}$ plants showed a rachilla length w: was approximately intermediate between the parents. The $F_{2} p c$ lation ranged between the two parents although in no year were $\mathrm{pl}$ obtained with rachillas reaching the extremes of the parents.

The variation in length of rachilla from parent to parent in $F_{2}$, with the mean of the population approximately midway betw them and also a gradual falling off in numbers in the classes from mid point to the two extremes, suggests that the inheritance of length of rachilla can probably be best explained on a multiple fa basis. 
If the factors concerned in the inheritance of this character were equal value and had a cumulative effect, a normal frequency curve ould be expected in plotting any $F_{2}$ distribution. As may be seen om Table 4, the type of curve obtained in plotting the $F_{2}$ distributions tained in any year shows a considerable variation from a normal equency curve. Skew curves such as the ones obtained suggest that e factors involved are either of unequal value in determining the ngth of rachilla or are modified by factors of unequal value.

\section{IREEDING BEHAVIOR OF $F_{3}$ PROGENIES FOR LENGTH OF RACHILLA}

Sixty-one $F_{2}$ plants from the $1924 \mathrm{~F}_{2}$ generation were grown $\mathrm{F}_{3}$ families in order to test their breeding behavior for the inheritce of the length of rachilla. One of these families, 18-2-48 row 290, oduced only seven plants. No measurements were made on these ants due to the lack of sufficient numbers. In subsequent tables this Imily is left out of consideration thus leaving 60 families on which reasurements for length of rachilla were obtained. The $F_{2}$ plant bm which this family was grown was continued in $F_{3}$, even if there re only a few seeds available because it seemed to be a False Wild ct plant. This proved to be the case as shown by its behavior in te $F_{3}$.

In four other $F_{3}$ families, 18-4-77, 18-5-31, 19-1-65, and 19-4-27 te number of plants matured were $45,43,38$, and 15 , respectively. ie small number of plants in these families was due to lack of seed. I all other cases 50 plants were used for making length of rachilla cterminations. The data obtained in measuring the length of rachilla c the $F_{3}$ families and of the parental material grown with these are sown in tables 20,21, and 22 of the appendix.

ln choosing the $F_{2}$ plants for continuing in the $F_{3}$, a number from ech class for length of rachilla were chosen. The number from each c.ss was approximately in proportion to the total number in that ss in the entire $F_{2}$ population, except that nearly all the plants in extreme classes were included. The plants were also chosen so it they would afford a test for the breeding hehavior of the other caracters studied.

A comparison of the distribution of the entire $F_{2}$ population and c the $F_{2}$ plants selected for continuing in the $F_{3}$ is shown in Table 5 .

A distribution was obtained which represented the $F_{2}$ population frly well, except for the extreme classes where proportionally more p.nts were included than in the intermediate classes. If the inheritase of length of rachilla is explained on a multiple factor basis, it 
TABLE 5.-Comparison of the total number of $F_{2}$ plants, grown in 1924, various classes for length of rachilla and the number from each class co tinued in $F_{3}$ progenies.

\begin{tabular}{c|c|c|c|c|c|c|c|c|}
\hline \hline Plant Designations & \multicolumn{6}{|c|}{ Classes for Length of Rachilla in Units of .1 mm. } \\
\hline & $15-16$ & $\mathbf{1 7 - 1 8}$ & $\mathbf{1 9 - 2 0}$ & $\mathbf{2 1 - 2 2}$ & $\mathbf{2 3 - 2 4}$ & $\mathbf{2 5 - 2 6}$ & $\mathbf{2 7 - 2 8}$ \\
\hline Total No. $\mathrm{F}_{2}$ plants & 4 & 44 & 157 & 191 & 97 & 32 & 4 \\
\hline F plants tested in $\mathrm{F}_{3}$ & 4 & 6 & 12 & 19 & 9 & 7 & 3 \\
\hline \hline
\end{tabular}

would be expected that there would be a greater probability of th extremes breeding true for a certain length of rachilla than any of th intermediate classes. For this reason more of the extreme classes wer included.

\section{CORRELATION BETWEEN $F_{2}$ PLANTS AND THEIR $F_{3}$ PROGENIES}

In order to determine to what degree the length of rachilla inherited, a correlation coefficient was calculated for the means of th $F_{2}$ plants continued in the $F_{3}$ and the means of these $F_{3}$ families. Th distributions are shown in Figure 4.

\begin{tabular}{|c|c|c|c|c|c|c|c|c|c|c|c|c|}
\hline \multirow{15}{*}{ E } & & \multicolumn{10}{|c|}{ Mean Length of Rachilla in $F_{3}$} & \\
\hline & & 17 & 18 & 19 & 20 & 21 & 22 & 23 & 24 & 25 & 26 & Tot: \\
\hline & 16 & 2 & 2 & & & & & & & & & \\
\hline & 17 & & 1 & 2 & & & & & & & & \\
\hline & 18 & & 2 & 1 & & & & & & & & \\
\hline & 19 & & 2 & 1 & 1 & 2 & & & & & & 6 \\
\hline & 20 & & & & 1 & 4 & 1 & & & & & 6 \\
\hline & 21 & & & & 5 & 3 & 1 & 1 & & & & 10 \\
\hline & 22 & & & & 1 & 4 & 4 & & & & & 9 \\
\hline & 23 & & & & & & 2 & 1 & 1 & & & 4 \\
\hline & 24 & & & & & & 4 & 1 & & & & 5 \\
\hline & 25 & & & & & & 1 & & 2 & & & 3 \\
\hline & 26 & & & & & & & 1 & 1 & 1 & I & 4 \\
\hline & 27 & & & & & & 1 & & 1 & & & 2 \\
\hline & 28 & & & & & & & & & & 1 & I \\
\hline \multicolumn{2}{|c|}{ Total } & 2 & 7 & 4 & 8 & 13 & 14 & 4 & 5 & 1 & 2 & 60 \\
\hline
\end{tabular}

Fig. 4.-Correlation between average length of rachilla in $F_{2}$ plants and the mea length of rachilla in their $F_{3}$ progenies. 
The coefficient obtained, $r=0.886 \pm 0.019$, indicates that length $f$ rachilla is an exceptionally stable size character, and that the $F_{2}$ ives a good indication of what may be expected in the $F_{3}$ progeny rom any plant.

\section{VARIABILITY IN $F_{3}$ PROGENIES}

The coefficient of variability was used as a criterion for deterining which $F_{3}$ families were breeding true for certain rachilla lengths nd which appeared to be heterozygous for the factors determining is character.

The coefficients of variability ranged from $2.55 \pm 0.18$ to $3.61 \pm$ 24 for the various plots of the Early Gothland parent grown in 1925 Table 20). In the Garton 784 parent this constant varied from $26 \pm 0.22$ to $5.01 \pm 0.34$ (Table 21 ). For the $F_{2}$ grown this year e coefficient is $8.28 \pm 0.19$ (Table 4). Omitting family 19-5-13, hich segregated for false wild oats and is therefore not considered this comparison, the $F_{3}$ progenies varied from $4.06 \pm 0.27$ to $9.09 \pm$ 61 (Table 22). In Table 6 a frequency distribution has been made the coefficients of variability and of mean length of rachilla for the fferent $\mathrm{F}_{3}$ families.

IBLE 6.-Variability in length of rachilla in the $F_{3}$ progenies grouped by classes for length of rachilla.

\begin{tabular}{|c|c|c|c|c|c|c|c|c|c|c|c|c|}
\hline \multirow{2}{*}{$\begin{array}{c}1 \text { an Length } \\
\text { Rachilla } \\
\text { units of } \\
.1 \mathrm{~mm} .\end{array}$} & \multicolumn{12}{|c|}{ Classes for Coefficient of Variability of the $F_{3}$ Progenies } \\
\hline & 4.0 & 4.5 & 5.0 & 5.5 & 6.0 & 6.5 & 7.0 & 7.5 & 8.0 & 8.5 & 9.0 & $\begin{array}{l}\text { 可 } \\
\text { 영 }\end{array}$ \\
\hline 17 & 1 & & & 1 & & & & & & & & 2 \\
\hline 18 & & & & & & & & 2 & 1 & 1 & 3 & 7 \\
\hline 19 & & & & 1 & & & & 1 & 1 & & 1 & 4 \\
\hline 20 & & & & 1 & 2 & & 1 & 1 & 2 & 1 & & 8 \\
\hline 21 & & & 3 & 1 & & 1 & 1 & 3 & 2 & 1 & 1 & 13 \\
\hline 22 & 1 & & & 3 & 5 & 1 & 1 & & 2 & & & 13 \\
\hline 23 & & & & 1 & 2 & 1 & & & & & & 4 \\
\hline 24 & & & 1 & 1 & 1 & 1 & & 1 & & & & 5 \\
\hline 25 & & 1 & & & & & & & & & & 1 \\
\hline 26 & & 1 & & 1 & & & & & & & & 2 \\
\hline otals & 2 & 2 & 4 & 10 & 10 & 4 & 3 & 8 & 8 & 3 & 5 & 59 \\
\hline
\end{tabular}


If the highest coefficient for the parental material $(5.01 \pm 0.34$ is taken as marking the upper limit of variability expected in line homozygous for a certain length of rachilla, we find there is one famil breeding true for a rachilla length of 17 , three for 21 , one for 22 , on for 24 , one for 25 , and one for 26 . Apparently one family has bee recovered breeding true for approximately the same length of rachill as the Garton 784 parent and also one with a rachilla approximatel as long as the Early Gothland parent. Between these extremes the are on this basis six other families breeding true for intermediat lengths. If a three factor difference with all factors of equal value $k$ assumed, it would be expected to recover one family breeding true $\mathrm{fc}$ each extreme and six intermediate homozygous families in a rando sample of 64 individuals. The distribution of the homozygous fan ilies among the various intermediate classes for length of rachilla not in very close agreement with what would be expected on such three factor basis. The $F_{3}$ breeding behavior supports the theory th: the inheritance of length of rachilla may be put on a multiple fact basis, and also that the factors concerned are either not of equal valt or are modified by factors of unequal value.

\section{INHERITANCE OF OTHER CHARACTERS}

The inheritance of ligule, panicle type, color, and rachilla pub scence was studied both independently and in their interrelation each other and to the length of rachilla.

\section{Inheritance of Ligule}

The Early Gothland parent in this cross had a leaf with a promi ent ligule at the juncture of the leaf blade with the leaf sheath, whi the Garton 784 parent was without a ligule. The ligule is ordinari a very easy character to classify in inheritance. Occasionally, hor ever, a plant is found where the ligule is so poorly developed that resembles a liguleless plant. In the $60 \mathrm{~F}_{2}$ plants continued in $F_{3}$ or plant should have been classed as liguled that was classed as ligulele and one plant where the opposite was the case (Table 23). The ? plants were all liguled indicating that the liguleless character is $r$ cessive.

Table 7 presents the results obtained with this character in t] $F_{2}$ population.

The results obtained are practically identical with the calculate ratio when it is assumed that the inheritance of this character is due two independently inherited duplicate factors. Love and Craig (1. found that inheritance of ligule was due to a one factor difference 
ABLE 7.-Inheritance of ligule in the $F_{2}$ generation.

\begin{tabular}{c|c|c|c|c|c}
\hline Year & \multicolumn{1}{|c|}{ No. of $F_{2}$ Plants } & Deviation & $\begin{array}{c}\text { Probable } \\
\text { Error }\end{array}$ & $\frac{D_{\text {Dev. }}}{\text { P. E. }}$ \\
\hline 1923 & Liguled & Liguleless & & & \\
\hline 1924 & 270 & 20 & & & \\
\hline 1925 & 495 & 34 & & & \\
\hline ibserved total & 111 & 25 & & & \\
\hline alculated 15:1 ratio & 1176 & 79 & & & \\
\hline \hline
\end{tabular}

sme varieties of oats and two in others. Garber (5) found a two ictor difference for the inheritance of this character. Nilsson-Ehle 13) found that this character segregated in a monohybrid ratio in ne cross while in others its inheritance could be explained on the asis of a two or three factor difference.

In all the different $F_{2}$ populations grown it was found that the zuleless condition was very closely associated with the side type of anicle. On account of this relationship between these two characters is necessary to take both into consideration in analyzing the data ir either one in the $F_{3}$.

If the liguled condition is dependent upon a two factor difference the $F_{2}$ generation indicates, it would be expected that all liguleless plants would breed true in the $F_{3}$ generation while some of the zuled forms would breed true for this condition and others segregate. one-half of the segregating lines a 15 to 1 ratio would be expected id in the others a monohybrid ratio.

With the one exception previously mentioned all liguleless $F_{2}$ ants continued in the $F_{3}$ bred true for this condition. Evidently this ant should have been classed as liguled. The breeding behavior of e $F_{2}$ plants in the $F_{3}$ progenies for the various characters studied is ven in Table 23 of the appendix.

\section{Inheritance of Panicle Type}

The Early Gothland parent has an open, spreading panicle while arton 784 is characterized by a side or "horsemane" type of panicle. 're $F_{1}$ plants were all intermediate. There seemed to be considerable iriation in the expression of this character, some of the $F_{1}$ plants sembling the open type more than the side type while in others the verse was true. The expression of this character appears to be inienced considerably by the environmental conditions and by the ige of maturity of the plants. 
The inheritance of panicle type was apparently closely associate with or influenced by the factors producing the liguleless conditio: No open liguleless forms were found among any of the $F_{2}$ populatios grown. This relation suggests that there either is a very close linkas between one of the factors for ligule and the factor or factors $f_{c}$ panicle type or that the absence of both of the factors for the ligule condition prevents the factor or factors for open panicle from fun tioning. Since no open liguleless plants were found among the 125 $\mathrm{F}_{2}$ plants grown, it was assumed that the latter was the case. On th assumed basis that the liguled condition is dependent on independen ly inherited duplicate factors and the open panicle type depends on single factor difference independent of the two factors for ligule, bi inhibited from functioning by the absence of both of the factors $f$, ligule, it would be expected to obtain in $F_{2}$ a proportion of $45: 15: 4$, open panicled liguled plants, side panicled liguled, and side panicle liguleless plants, respectively, or a proportion of 45 open to $19 \mathrm{sic}$ panicled plants. The results obtained and the calculated numbe are presented in Table 8.

TABLE 8.- Inheritance of panicle type in the $F_{2}$ generation.

\begin{tabular}{|c|c|c|c|c|c|}
\hline \multirow{2}{*}{ Year } & \multicolumn{2}{|c|}{ No. of $F_{2}$ Plants } & \multirow{2}{*}{ Deviation } & \multirow{2}{*}{$\begin{array}{c}\text { Probable } \\
\text { Error }\end{array}$} & \multirow{2}{*}{$\frac{\text { Dev. }}{\text { P. E. }}$} \\
\hline & Open Panicle & Side Panicle & & & \\
\hline$\lcm{923}$ & 191 & 99 & & & \\
\hline 1924 & 380 & 149 & & & \\
\hline 1925 & 280 & 156 & & & \\
\hline Observed total & 851 & 404 & & & \\
\hline Calculated $45: 19$ ratio & 882.4 & 372.6 & 31.4 & 10.92 & 2.88 \\
\hline
\end{tabular}

The agreement of the observed with the calculated is fairly goo the difference being 2.88 times its probable error. In one out of chances a deviation as large as this might be expected from rando sampling and, therefore, the hypothesis appears plausible. The population grown in 1924 agrees much better with the theoretic than do those grown in either of the other two years, the deviation b ing only a little more than its probable error. The $F_{3}$ breeding $b$ havior of the $F_{2}$ plants grown in 1924 shows that the classifization $f$ punicle type was relatively free from errors. One plant was evident classed as side which should have been classed as open while in a other case the reverse was true. 
The breeding behavior of the $F_{2}$ plants grown in 1923 when sted in $F_{3}$ progenies shows that two plants classified as side in that :ar should have been classed with the open panicled class. These ants segregated for panicle type and, therefore, were heterozygous $r$ this character. The high percentage of side panicle plants in the )25 $F_{2}$ population suggests that in this year, also, probably a numer of the plants classed as side panicled were actually heterozygous r this character and should have been classed with the open panicle rms. When the fact is taken into consideration that this character ems to be considerably influenced by environment and thus overpping of classes is likely to occur, the data undoubtedly support the eory that in this cross the inheritance of panicle type is due to a igle factor difference.

When the two characters, ligule and panicle type, are considered gether the results shown in Table 9 were obtained.

TABLE 9. - Inheritance of ligule and panicle type in the $F_{2}$ generation.

\begin{tabular}{|c|c|c|c|c|}
\hline \multirow{2}{*}{ Year } & \multicolumn{2}{|c|}{ Ligule Present } & \multicolumn{2}{|c|}{ Ligule Absent } \\
\hline & Open & Side & Open & Side \\
\hline 1923 & 191 & 79 & 0 & 20 \\
\hline 1924 & 380 & 115 & 0 & 34 \\
\hline 1925 & 280 & 131 & 0 & 25 \\
\hline Observed total & 851 & 325 & 0 & 79 \\
\hline Calculated $45: 15: 4$ ratio & 882.4 & 294.1 & 0 & 78.4 \\
\hline
\end{tabular}

$$
\mathrm{X}^{2}=4.368 \quad \mathrm{P}=0.116
$$

Without correcting for the apparent errors in classification in 23 and 1925, the observed shows only a fair agreement with the culated, $\mathrm{P}=0.116$ or 12 times in 100 trials would deviations great as these be expected from chance selection. If the 1924 Fpulation alone is considered, the fit is very close; the calculated ing 372,124 , and 33 , while the observed were 380 , 115, and 34 the three classes, respectively. $\mathrm{X}^{2}$ is less than one showing a very cise fit. The data give further evidence in support of the assumed torial analysis for the inheritance of ligule and panicle type.

A summary of the breeding behavior for ligule and panicle type the $F_{3}$ progenies grown from the $1924 F_{2}$ plants in the five-row its is given in Table 10 . 
TABLE 10.-Breeding behavior for ligule and panicle type of the $F_{3}$ progen grown in 5-row plots in 1925.

\begin{tabular}{|c|c|c|c|c|c|c|c|c|c|c|}
\hline \multirow{3}{*}{$F_{2}$ Plants } & \multirow{3}{*}{$\begin{array}{c}\text { Number } \\
\text { of } F_{2} \\
\text { Plants }\end{array}$} & \multicolumn{9}{|c|}{$F_{3}$ Progenies } \\
\hline & & \multicolumn{3}{|c|}{ Liguled } & \multicolumn{3}{|c|}{ Seg. for Ligule } & \multicolumn{3}{|c|}{ Liguleless } \\
\hline & & ฮัँ & $\dot{\ddot{n}}$ & $\stackrel{\Xi}{\pi}$ & 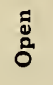 & $\begin{array}{l}\dot{g} \\
\dot{\varphi n n}\end{array}$ & $\varpi_{\tilde{n}}$ & §̊ & $\begin{array}{l}\dot{8} \\
\tilde{0}\end{array}$ & $\dot{y}$ \\
\hline Open liguled & 21 & 8 & 6 & 1 & & 6 & & & & \\
\hline Corrected & 20 & 8 & 6 & 0 & & 6 & & & & \\
\hline Side liguled & 22 & & & 1 & & & 20 & & & \\
\hline Corrected & 23 & & & 2 & & & 21 & & & \\
\hline Side liguleless & 17 & & & & & & 1 & & & 1 \\
\hline Corrected & 17 & & & & & & 0 & & & 1 \\
\hline Total (Corrected) & 60 & 8 & 6 & 2 & & 6 & 21 & & & $\overline{1}$ \\
\hline Calculated & 60 & 3.1 & 6.2 & 10.7 & & $\overline{10.6}$ & 12.3 & & & $\overline{1}$ \\
\hline
\end{tabular}

The $21 \mathrm{~F}_{2}$ plants classed as open-liguled bred as follows in $t$ $\mathrm{F}_{3}$ progenies: Eight bred true to the open-liguled condition, six $\mathrm{br}$. true for ligule but segregated for panicle, one bred true for sid liguled, and six segregated for both ligule and panicle. The $F_{2}$ pla producing the side-liguled progeny should evidently have been clas fied as side-liguled in the $F_{2}$ and has, therefore, been added to $t$ class in the corrected tabulation.

The number of families in each class obtained from the ope liguled plants agrees fairly well with the calculated.

With the exception of one plant which segregated for ligule the $F_{2}$ plants classed as liguleless bred true for this condition. In $t$ corrected totals the plant segregating for ligule is classed with the sid liguled plants.

All of the $F_{2}$ plants classified as side-liguled and continued in $t$ $\mathrm{F}_{3}$ bred true for side panicle. One plant bred true for the ligulele condition. It should evidently have been classified as liguleless as has been put with this class in the corrected totals.

Of the 23 side-liguled $F_{2}$ plants on the corrected basis two br true for ligule and 21 segregated. The calculated proportion is 10 liguled to 12.3 segregating. In this case the observed does not agr very well with the theoretical. Although the numbers are small, 
would seem that for some undetermined reason more of the heterozygous side-liguled plants were selected than of the homozygous ones for continuance in $F_{3}$. Some factor may also be present which causes a modification of the expected ratios in this class.

In addition to the foregoing test of the $1924 \mathrm{~F}_{2}$ plants, 15 additional progenies were grown in single rows. It is realized that the number of plants grown is too small to obtain any definite ratios. The chief aim was to find out if the side and liguleless condition bred true. The results obtained are given in Table 24 of the appendix. Only side panicled plants were used in this supplementary test. All liguleless plants bred true for this condition. One of the side-liguled plants segregated for panicle type and evidently should have been classed ss open in the $F_{2}$. Two of the other nine side-liguled plants bred true for this condition while seven segregated. Here again the proportion of side-liguled plants breeding true is too small as compared with the :alculated.

In addition to the foregoing tests of the $F_{2}$ plants grown in 1924 , 55 single row families were grown from the $1923 \mathrm{~F}_{2}$ plants. The reiults obtained are shown in Table 25 of the appendix. A summary is oresented in Table 11 .

AABLE 11.-Breeding behavior of $F_{3}$ progenies from $1923 F_{2}$ plants grown in single rows in 1925 .

\begin{tabular}{|c|c|c|c|c|c|c|c|c|c|c|}
\hline \multirow{3}{*}{$F_{2}$ Plants } & \multirow{3}{*}{$\begin{array}{c}\text { Number } \\
\text { of } \mathrm{F}_{2} \\
\text { Plants }\end{array}$} & \multicolumn{9}{|c|}{$F_{3}$ Progenies } \\
\hline & & \multicolumn{3}{|c|}{ Liguled } & \multicolumn{3}{|c|}{ Seg. for Ligule } & \multicolumn{3}{|c|}{ Liguleless } \\
\hline & & ठ̊̊ & $\begin{array}{l}\dot{0} \\
\tilde{n}^{n}\end{array}$ & $\stackrel{0}{\circ \pi}$ & పิ & 离 & تֶّ & $\begin{array}{l}\tilde{\partial} \\
\text { o̊ }\end{array}$ & ڤั่ & : \\
\hline pen liguled & 11 & 3 & 6 & & & 2 & & & & \\
\hline forrected & 13 & 3 & 7 & & & 3 & & & & \\
\hline ide liguled & 34 & & 1 & 3 & & 1 & 29 & & & \\
\hline Oorrected & 33 & & 0 & 3 & & 0 & 30 & & & \\
\hline ide liguleless & 15 & & & & & & 1 & & & 14 \\
\hline orrected & 14 & & & & & & 0 & & & 14 \\
\hline otal (Corrected) & 60 & 3 & 7 & 3 & & 3 & 30 & & & 14 \\
\hline alculated & 60 & 2.0 & $\overline{4.0}$ & 15.4 & & 7.0 & 17.6 & & & 14 \\
\hline
\end{tabular}


Two plants classified as side panicled in 1923 segregated fo panicle in the $F_{3}$ test in 1925 . They evidently were heterozygous anc should have been classed with the open panicle group. Likewise on of the plants classed as liguleless was heterozygous. Again in thi test there were too many of the side-liguled $F_{2}$ plants segregating fo ligule in the $F_{3}$ progenies as compared with the class breeding tru for ligule and side panicle.

In the three tests made of the breeding behavior of ligule anc panicle type in the $F_{3}$ progenies, the results obtained agree fairly satis factorily with the calculated except in the case of the proportion o progenies breeding true for the side-liguled condition and those segre gating for ligule and breeding true for side panicle. The results in dicate therefore that panicle type is conditioned by a single facto difference. It also seems safe to conclude that the presence of botl factors for the liguleless condition in the homozygous state prevent the development of an open panicle.

Nilsson-Ehle (13) explained the inheritance of panicle type or the basis of one, two, and three factor differences in various oa croses. A very close association was found between panicle typ and ligule in certain crosses. No open liguleless forms were obtainec in is:1y of the crosses made. In one cross between an open-liguler variety and a liguleless side--panicle variety, the results obtained wer explained on the basis that two independent duplicate factors fo ligule were present in the liguled parent and that both of these factor: had an influence on the panicle type. The presence of one of thest factors alone would produce an intermediate panicle. The other facto alone would produce an intermediate panicle also, but more densi than the former while the absence of both would 'result in a sid panicle. In other crosses there were apparently factors for panicl type present which did not influence the ligule and also factors which would produce a ligule but did not affect the panicle type.

Quisenberry (15) found a two factor difference for panicle typ in the oat cross which he studied. Gaines (..$)$ and also Wakabaysh (19) found irregular segregation for panicle type in the $F_{2}$ generatior and obtained forms breeding true for the intermediate condition a! well as for open and side panicles in the $F_{3}$ progenies. Garber (4), obtained results indicating a one factor difference for the inheritanci of panicle type. 


\section{Inheritance of Color}

In this cross the Early Gothland has a white grain while the color if the Garton 784 grain is black. The plants in the cross were either lassed as black or white, no attempt being made to make further livisions on the basis of intensity of the color. The $F_{1}$ plants all had lack seed indicating that black is dominant. The segregation in the

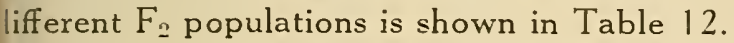

ABLE 12.-Inheritance of color of grain in the $F_{2}$ generation.

\begin{tabular}{|c|c|c|c|c|c|}
\hline \multirow{2}{*}{ Year } & \multicolumn{2}{|c|}{ Number of $\mathrm{F}_{2}$ Plants } & \multirow[b]{2}{*}{ Deviation } & \multirow{2}{*}{$\begin{array}{c}\text { Probable } \\
\text { Error }\end{array}$} & \multirow{2}{*}{$\frac{\text { Dev. }}{\text { P. E. }}$} \\
\hline & Black & White & & & \\
\hline 1923 & 223 & 67 & & & \\
\hline 1924 & 403 & 126 & & & \\
\hline 1925 & 309 & 127 & & & \\
\hline bserved total & 935 & 320 & & & \\
\hline alculated $3: 1$ ratio & 941.25 & 313.75 & 6.25 & 10.32 & 0.61 \\
\hline
\end{tabular}

The observed numbers agree very closely with a 3:1 ratio and idicate that color in this cross is due to a single factor difference.

In classifying the $F_{3}$ lines for color of grain the first fifteen plants ere used as a basis for the determination, except in ten of the segreating lines where a count was made for a verification of the $F_{2}$ ratios. summary of the breeding behavior for color of the $F_{3}$ lines is given Table 13.

ABLE 13.-Summary of breeding behavior for color of the $F_{3}$ progenies.

\begin{tabular}{|c|c|c|c|c|}
\hline \multirow{2}{*}{ Color of $F_{2}$ Plant } & \multicolumn{4}{|c|}{$F_{3}$ Breeding Behavior } \\
\hline & Black & Segregating & White & Total Families \\
\hline ack & 13 & 27 & & 40 \\
\hline hite & & & 20 & 20 \\
\hline sserved & 13 & 27 & 20 & 60 \\
\hline ilculated & 13.3 & 26.7 & 20 & 60 \\
\hline
\end{tabular}

All $F_{2}$ plants classed as white bred true for this color while those assified as black segregated in the ratio of 13 to 27 for lines breeding ue for black and lines segregating for color. The calculated is 13.3 26.7. The $F_{3}$ breeding behavior, therefore, verifies the assumption 
that a one factor difference is concerned in the inheritance of this char. acter. These results are in agreement with results obtained by Love and Craig (10), Gaines (3), Garber and Quisenberry (6), and othes workers. Nilsson-Ehle (13) found three separately inherited colos factors each allelomorphic to its absence in a certain oat cross. Through the interaction of these factors four classes for color were obtained, black, gray, yellow, and white. Other workers have alsc reported similar results when certain crosses were made.

\section{Inheritance of Rachilla Pubescence}

The study of the inheritance of pubescence on the rachilla was based on the rachilla of the lower grain. The Early Gothland paren has a rachilla usually with a number of rather fine hairs. The Gartor 784 parent has a smooth rachilla with only an occasional hair on some grains. In classifying plants for this character the five seeds from each plant used for making rachilla measurements were also used for mak. ing the pubescence determination. A plant was classed as hairy i. any hairs were found on any of the grains examined. Since an occa. sional hair is sometimes found in the smooth parent this classificatior results in some overlapping of classes. The $F_{1}$ plants all had smooth rachillas. The results obtained in the $F_{2}$ populations are given ir Table 14.

TABLE 14.- Inheritance of rachilla pubescence in the $F_{2}$ generation.

\begin{tabular}{|c|c|c|c|c|c|}
\hline \multirow{2}{*}{ Year } & \multicolumn{2}{|c|}{ Number of $F_{2}$ Plants } & \multirow{2}{*}{ Deviation } & \multirow{2}{*}{$\begin{array}{c}\text { Probable } \\
\text { Error }\end{array}$} & \multirow{2}{*}{$\frac{\text { Dev. }}{\text { P. E. }}$} \\
\hline & Smooth & Hairy & & & \\
\hline 1923 & 225 & 65 & & & \\
\hline 1924 & 355 & 174 & & & \\
\hline 1925 & 331 & 105 & & & \\
\hline Observed total & 911 & 344 & & & \\
\hline Calculated $3: 1$ ratio & 941.25 & 313.75 & 30.25 & 10.32 & 2.94 \\
\hline
\end{tabular}

The total observed numbers agree fairly well with the calculated the deviation being slightly less than three times its probable error The proportions in the years 1923 and 1925 agree very closely witl the calculated 3:1 ratio while in 1924 there were too many in thi hairy class. It would seem that for some reason there was more over lapping of classes for this character in this year than in the other two A check on this is afforded by the breeding behavior of the $60 \mathrm{~F}$ progenies grown from $1924 \mathrm{~F}_{2}$ plants and which were classified fo this character. 
In classifying the $F_{3}$ families for rachilla pubescence the first fifen individuals were used as a basis for classifying the families. In a uber of the segregating families counts were made of the proporin of smooth and hairy individuals in order to check the ratios obined in the $F_{2}$ generation.

A summary of the breeding behavior for rachilla pubescence in $F_{3}$ progenies is shown in Table 15 .

BLE 15. - Summary of breeding behavior for rachilla pubescence in the $F_{3}$ progenies.

\begin{tabular}{l|c|c|c|c}
\hline \multirow{2}{*}{ Issification of $F_{2}$ Plant } & \multicolumn{3}{|c|}{$F_{3}$ Breeding Behavior } & Total Families \\
\cline { 2 - 4 } & Smooth & Segregating & Hairy & \\
\hline ooth & 14 & 27 & $\frac{1}{14}$ & 42 \\
\hline iry & & 4 & 14 & 18 \\
\hline served (Corrected) & 14 & 31 & 15 & 60 \\
\hline lculated & 15 & 30 & 15 & 60 \\
\hline
\end{tabular}

From the $42 \mathrm{~F}_{2}$ plants classified as smooth, 14 lines bred true for is condition, 27 segregated for smooth and hairy, and one bred true ir the hairy condition. Evidently this latter plant should have been issified as hairy in the $F_{2}$. Fourteen of the $F_{2}$ plants, classified as iry, bred true, while four segregated. On the assumed basis of a e factor difference with smooth condition dominant, these four ants should have been classified as smooth in the $F_{2}$. When these plants are reclassified on the basis of their breeding behavior the imber of lines breeding true and the number segregating agree very isely with the calculated. The observed are 14 to 31 , and the callated 15 to 30 , respectively. The $F_{3}$ breeding behavior, therefore, rifies the assumption that rachilla pubescence in this cross is due to \#ingle factor difference with smooth rachilla dominant.

On the basis of the breeding behavior in the $F_{3}$ and assuming at the same proportion of overlapping of classes occurred in the nainder of the $F_{2}$ classification in 1924,30 plants should be changed fim the hairy class to the smooth class in the $1924 \mathrm{~F}_{2}$ population. If ts were done, the observed and calculated totals for the three years "suld be:

$\begin{array}{lrr} & \text { Smooth } & \text { Hairy } \\ \text { Observed } & 941 & 314 \\ \text { Calculated } & 941.25 & 313.75\end{array}$

A number of individuals were, no doubt, classed in the wrong sup in the other years, also, so that the close fit is probably coincicntal. 
Surface (17) found that pubescence of the rachilla together wi six other characters were completely linked with wild base in a cro between wild and cultivated oats. These were all inherited in a mon hybrid ratio. Absence of rachilla hairs was found dominant to th hairy condition.

\section{INTERRELATION OF CHARACTERS}

In order to determine if any of the characters studied tended be associated in their inheritance, the $F_{2}$ plants were classified various combinations. The breeding behavior of the $F_{3}$ progenit shows that some of the $F_{2}$ plants were wrongly classified for rachil pubescence. Since only the $1924 \mathrm{~F}_{2}$ can be checked from the breedir behavior of the $F_{3}$ progenies, the $F_{2}$ grown in this year is used in th. various groupings where rachilla pubescence is one of the characte: studied. With the exception of the relation found between the ligul character and panicle type, which has already been discussed, n association in inheritance was found between any of the qualitativ characters studied. Table 16 is presented as typical of the metho used. All the different qualitative characters studied are included $\mathrm{i}$ this table.

In Table 16 the correction for pubescence has been applied as $\mathrm{i}$ the other tests with this character. The deviation from the calculate is such as might be expected by chance two times in five trials, $\mathrm{P}=$ 0.410 . From these tests it seems safe to conclude that the four chai acters are all conditioned by factors that are independently inherite and that the relation between the factor differences which cause panicl type and the liguled condition is of the nature assumed.

\section{CORRELATION OF RACHILLA LENGTH WITH OTHER CHARACTERS}

In order to determine if there is any correlation between th inheritance of length of rachilla and any of the other character studied, the means were calculated for the $F_{2}$ plants in each contrast ing class for the various characters. If there was no significant differ ence found in the means between any two contrasted classes it wa concluded that no correlation existed between that particular characte and the length of rachilla. In addition to this test the means for lengtl of rachilla of the $F_{3}$ progenies breeding true for the contrasted char acters and those segregating were thrown into frequency distribution: from which a mean of means was calculated for each class. The rela tionship between any character and the length of rachilla could thu: be studied in these progenies and the results could then be used as : check on the results obtained in the $F_{2}$ generation. 


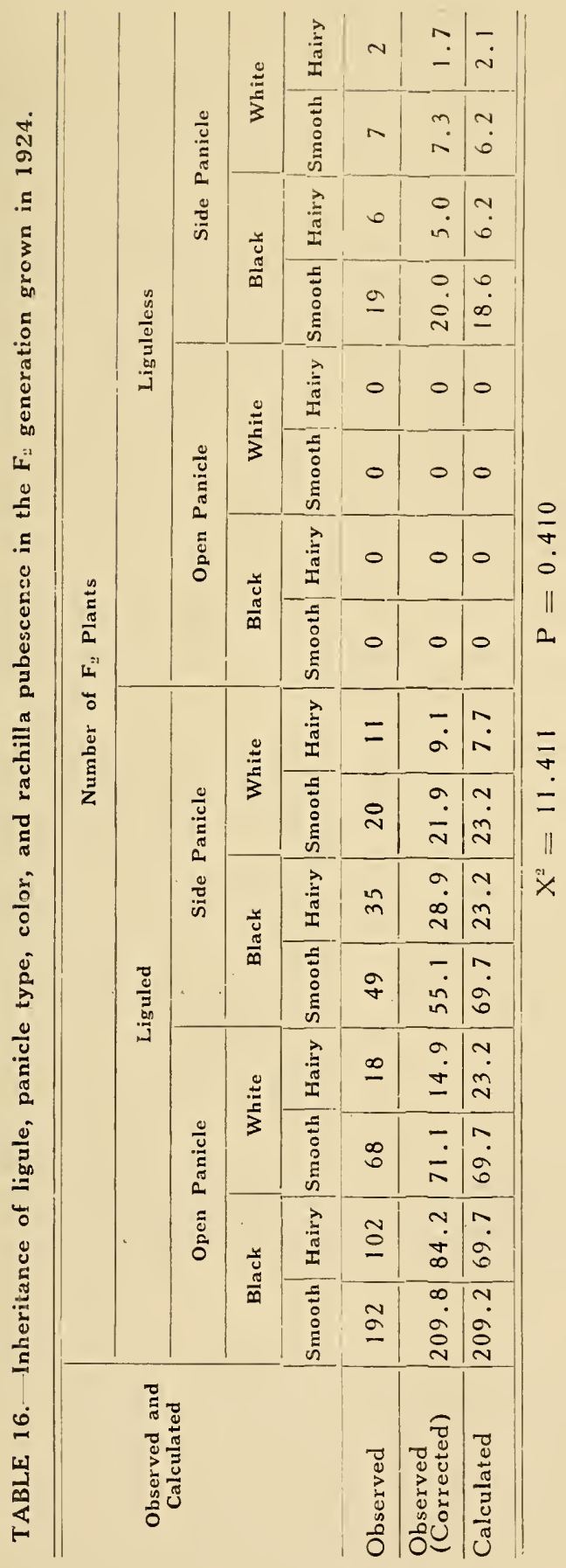




\section{Pubescence and Length of Rachilla}

In Table 17 the means for the pubescent and the smooth segr gates in the $F_{2}$ populations and the means for the $F_{3}$ progenies bree ing true for the hairy condition, segregating, and breeding true $f$ smooth rachilla are compared.

The data show that in all three $F_{2}$ populations the means for th length of rachilla were greater for the hairy segregates than for th smooth and in no case was the difference less than ten times its prol able error. This is taken as evidence that the characters pubescen of rachilla and length of rachilla are definitely associated in inheritanc

As a further test of this relationship, coefficients of contingen were calculated for pubescence and length of rachilla in the $F_{2}$ gener tions. The following coefficients were obtained in the various I populations: $1923, \mathrm{C}=0.346 \pm 0.046 ; 1924, \mathrm{C}=0.416$ $0.033 ; 1924, C=0.321 \pm 0.039$. In all three years there was positive correlation between these two characters. This method, analysis, therefore, also shows the linkage relation which exists b tween pubescence and length of rachilla in their inheritance.

When the $F_{3}$ generation is considered it is also seen that th families breeding true for the hairy condition had a greater mea length of rachilla than either the segregating families or those breedin true for smooth rachilla. The families segregating for this characte also had a greater mean length of rachilla than those breeding tru for the smooth condition. In no case was the difference less tha three times its probable error. This is further confirmation that thes two characters are definitely associated in inheritance.

Since it has been shown that the inheritance of pubescence of th rachilla is dependent upon a single factor difference and that th length of rachilla may be explained on a multiple factor basis, it seer logical to conclude that the factor determining the inheritance of $\mathrm{pr}$ bescence of the rachilla is in the same linkage group as one or mor of the factors determining the length of rachilla. 


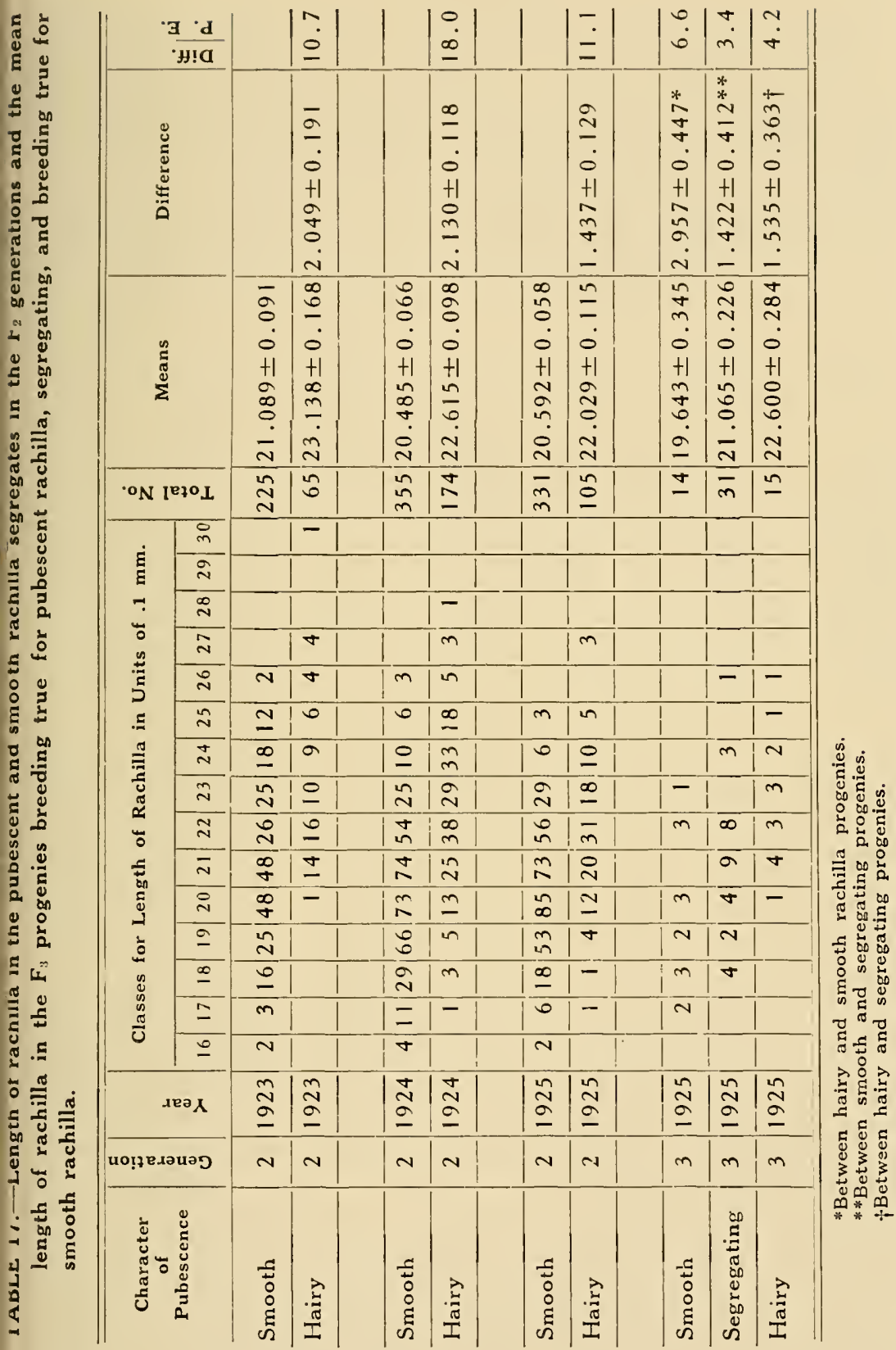




\section{Ligule, Panicle Type, Color of Grain, and Length of Rachilla}

The means for length of rachilla of the various classes for ligule, panicle type, and color were calculated in the same manner as these were calculated for the classes for pubescence of the rachilla. A summary of the results obtained is given in Table 18 .

TABLE 18.- Mean length of rachilla in different contrasted classes in the $F_{2}$ and $F_{2}$ generations.

\begin{tabular}{|c|c|c|c|c|c|c|c|}
\hline \multirow{3}{*}{ Description } & \multirow{3}{*}{ 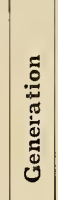 } & \multicolumn{6}{|c|}{ Number of Plants and Mean Length of Rachilla in Units of $.1 \mathrm{~mm}$} \\
\hline & & \multicolumn{2}{|r|}{1923} & \multicolumn{2}{|r|}{1924} & \multicolumn{2}{|r|}{1925} \\
\hline & & $\dot{z}$ & Means & $\dot{\dot{z}}$ & Means & $\dot{\mathrm{z}}$ & Means \\
\hline Liguled & $\mathrm{F}_{2}$ & 270 & $21.548 \pm 0.090$ & 495 & $21.178 \pm 0.065$ & 411 & $20.934 \pm 0.05$ \\
\hline Liguleless & $F_{2}$ & 20 & $21.550 \pm 0.311$ & 34 & $21.294 \pm 0.222$ & 25 & $21.000 \pm 0.27$ \\
\hline Liguled & $F_{3}$ & & & & & 16 & $20.875 \pm 0.33$ \\
\hline Seg. for ligule & $F_{3}$ & & & & & 27 & $21.370 \pm 0.29$ \\
\hline Liguleless & $\mathrm{F}_{3}$ & & & & & 17 & $20.882 \pm 0.29$ \\
\hline Open panicle & $F_{2}$ & 191 & $21.534 \pm 0.110$ & 381 & $21.097 \pm 0.074$ & 280 & $20.811 \pm 0.06$ \\
\hline Side panicle & $\mathrm{F}_{2}$ & 99 & $21.576 \pm 0.140$ & 148 & $21.412 \pm 0.114$ & 156 & $21.167 \pm 0.09$ \\
\hline Open panicle & $\mathrm{F}_{3}$ & & & & & 8 & $20.125 \pm 0.52$ \\
\hline Seg. for panicle & $F_{3}$ & & & & & 12 & $21.250 \pm 0.45$ \\
\hline Side panicle & $F_{3}$ & & & & & 40 & $21.250 \pm 0.20 t$ \\
\hline Black grain & $F_{2}$ & 223 & $21.453 \pm 0.102$ & 403 & $20.980 \pm 0.070$ & 309 & $20.861 \pm 0.06 t$ \\
\hline White grain & $\overline{F_{2}}$ & 67 & $21.866 \pm 0.158$ & 126 & $21.841 \pm 0.125$ & 127 & $21.126 \pm 0.09$ \\
\hline Black grain & $\mathrm{F}_{3}$ & & & & & 15 & $20.800 \pm 0.33 \varepsilon$ \\
\hline Seg. for color & $\mathrm{F}_{3}$ & & & & & 25 & $20.400 \pm 0.26 i$ \\
\hline White grain & $\mathrm{F}_{3}$ & & & & & 20 & $22.150 \pm 0.27$ \\
\hline
\end{tabular}

It is evident from a consideration of the data given in Table 18 that there was no correlation between the inheritance of the length of rachilla and the inheritance of either ligule or panicle type. The differences between the means for the various classes are not significant in the light of their probable errors. 
The differences in length of rachilla between the black and white ained classed in the $F_{2}$ generation for the three years were $0.413 \pm$ $188,0.861 \pm 0.143$, and $0.265 \pm 0.118$. In two out of the iree years the differences were not large enough to be considered sigficant. In the other year, 1924, the difference was approximately $x$ times its probable error and shows that the white seeded plants ad the longer rachillas that year. The fact that there is only a difrence in one year out of the three indicates that if this difference was se to inheritance, the association between color and length of rachilla very loose.

In the $F_{3}$ generation there was no significant difference in length rachilla between the families breeding true for black and those gregating for color. The actual length for the segregating families as less than for the families breeding true for black color. The difrences in mean length of rachilla between the segregating and white milies was $1.750 \pm 0.386$ units. This difference is significant in e light of its probable error. The difference between the black eded families and the white was $1.350 \pm 0.438$ which may also be insidered as significant. These results seem to point to a slight assoation between the inheritance of color and length of rachilla. 


\section{SUMMARY}

A cross was made between Early Gothland and Garton $7 \varepsilon$ two varieties of oats differing in certain characters. A study was mar of the inheritance of the length of the rachilla, ligule, panicle typ color, and pubescence of the rachilla. From the results obtained ce tain conclusions and deductions can be drawn.

1.- The length of rachilla was found to be a very stable si: character and was not greatly influenced by environmental condition

2. - The length of rachilla in the $F_{1}$ plants was intermediate $b$ tween the two parents. The $F_{2}$ individuals ranged from one parent the other for length of rachilla. From $60 \mathrm{~F}_{3}$ progenies grown, or apparently homozygous line was recovered with a rachilla length short as the short parent, and one $F_{3}$ family with a rachilla length a: proximately as long as the longer parent. Families apparently homoz gous for rachilla lengths intermediate between these extremes we also recovered. The inheritance of rachilla length can be explaine on the basis of multiple factors for length of rachilla. The results $i$ dicated that the factors involved were not of equal value in determi ing the length of rachilla.

3.-The ligule of the leaf was found to be determined by dup cate factors giving a ratio of 15 liguled to 1 liguleless plant in the generation.

4.- The panicle type was found to be controlled by a single fa tor difference. The presence of the two factors for the liguleless co dition in the homozygous state prevented the factor for open panicl if present, from functioning and resulted in producing a side panicl No open panicled liguleless forms were found.

5.-Black color of grain was dominant to white. Inheritan of color was controlled by a single factor difference.

6.-Pubescence of the rachilla was found to be recessive to t] smooth condition and was controlled by a single factor difference.

7.-No evidence of linkage was found between the factors $f$ ligule, panicle type, color, or pubescence. All seemed to be inherit independently of each other except for the duplicate relationship b tween the two factors for ligule and their common relationship to $t]$ factor for panicle type.

8.-No evidenze was found of linkage between any of the fa tors for length of rachilla and ligule or panicle type. Some of the da indicated a possible loose linkage between color and length of rachill

9. - A close linkage was found between at least one of the fa tors or group of factors for length of rachilla and the factor for pube cence of the rachilla. 


\section{SUPPLEMENT}

Since this paper was originally submitted for publication, addinal data have been obtained by growing $F_{4}$ families from a number selected $F_{3}$ plants. These $F_{4}$ families were grown during the sumar of 1926 and handled in a way similar to that in which the $F_{3}$ and ner material was handled in the previous years of the study. In all re were twelve $F_{4}$ families grown including progenies from single ints from each of the eight $F_{3}$ families which were apparently breedtrue for certain rachilla lengths. The data obtained are given in ble 26 of the appendix.

The highest coefficient of variability obtained in the parental terial grown in 1926 was $5.84 \pm 0.38$. If this is taken as the per limit for the coefficients of variability for homozygous lines it is ind that all but two of the $F_{4}$ lines are apparently homozygous. nong these are included all $F_{4}$ progenies from the $F_{3}$ families which re classed as homozygous and also two lines from $\mathrm{F}_{3}$ families which re classified as heterozygous. If an $F_{3}$ family were homozygous a certain length of rachilla it would be expected that it would conue to show this condition in the $F_{t}$ also. Either heterozygous or mozygous $F_{4}$ lines might be expected from a heterozygous $F_{3}$ family. I data show a very close correlation between the length of the rachilin the $F_{3}$ and $F_{4}$ generations.

The $F_{t}$ data substantiate the conclusion previously reached that a mber of $F_{3}$ families had been obtained that were breeding true for tain rachilla lengths.

Data on the other characters studied were also obtained for the families. These data are not presented here but in all cases they sstantiate the conclusions drawn from the study of the previous genetions. 


\section{LITERATURE CITED}

(1) Caporn, A. St. Clair

1918. AN ACCOUNT OF AN EXPERIMENT TO DETERMINE THE HEREDIT OF EARLY AND LATE RIPENING IN AN OAT CROSS. Jour. Genetic $7: 247-257$.

(2) EAST, E. M.

1916. StUdies on Size inheritanCE IN Nicotiana. Genetics, 1:16. 176.

(3) Gaines, E. G.

1917. INHERITANCE IN WHEAT, BARLEY, AND OAT HYBRIDS. Wash. Ag Exp. Sta. Bul. 135.

(4) GARBER, R. J.

1922. INHERITANCE AND YIELD WITH PARTICULAR REFERENCE TO RU! RESISTANCE AND PANICLE TYPE IN OATS. Univ. of Min: Tech. Bul. 7 .

(5)

1922. ORIGIN OF FALSE WIID OATS. Jour. Heredity, 13:40-48.

(6) -, AND Quissenberry, K. S.

1926. A STUDY OF CORRELATED INHERITANCE IN A CERTAIN AVEN cross. W. Va. Agr. Exp. Sta. Bul. 217.

(7) Griffee, Fred

1925. CORRELATED INHERITANCE OF BOTANICAL CHARACTERS IN BARLE AND MANNER OF REACTION TO HELMINTHOSPORIUM SATIVUI Jour. Agr. Res., 30:915-935.

(8) Hayes, H. K., and Garber, R. J.

1921. BREEDING CROP PLANTS. 328 pp. New York.

(9) Lindstrom, E. W.

1924. A GENETIC LINKAGE BETWEEN SIZE AND COLOR FACTORS IN TH томато. Science, $60: 182-183$.

(10) Love, H. H., ANd Craig, W. T.

1918. THE RELATION BETWEEN COLOR AND OTHER CHARACTERS IN CEI TAIN AVENA CROSSES. Am. Nat. $52: 369-383$.

(11)

1918. SMALl GRAin INVESTigations. Jour. Heredity 9:67-76.

(12) Nilsson-Ehle, H.

1908. EINIGE ERGEBNISSE VON KREUZUNGFN BEI HAFER UND WEIZEN Bot. Notiser, Lund., pp. 257-298.

(13)

1909. KREUZUNGSUNTERSUCHUNGEN AN HAFER UND WEIZEN. Lund Univ. Arsskr. N. F. Afd. 2, Bd. 5, Nr. 2, pp. 122.

(14) Noll, C. F.

1925. STUDIES OF INHERITANCE OF EARLINESS IN CERTAIN AVEN Crosses. Penn. Agr. Exp. Sta. Bul. 194.

(15) QUisenberRY, K. S.

1926. CORRELATED INHERITANCE OF QUANTITATIVE AND QUALITATIV Characters in 0ats. W. Va. Agr. Exp. Sta. Bul. 202. 
(9) SAX, KARL

1923. THE ASSOCIATION OF SIZE DIFFERENCES WITH SEED-COAT PATTERN and pigmentation in phaseolus vulgaris. Genetics 8:552560.

(Y) SuRface, F. M.

1916. STUDiES ON OAT BREEDING. III. ON THE INHERITANCE OF CERTAIN GLUME CHARACTERS IN THE CROSS AVENA FATUA $X$ AVENA Sativa Var. KHERSON. Genetics 1:252-286.

(3) Tedin, H., and Tedin, O.

1926. CONTRIBUTIONS TO THE GENETICS OF BARLEY. I. TYPE OF SPIKE, NAKEDNESS, AND height of PLANTS. Hereditas Ed. 7, Haft 2, $151-160$.

(7) WaKabYashi, S.

1921. A STUDY OF HYBRID OATS, AVENA STERILIS X AVENA ORIENTALIS. Jour. Am. Soc. Agron., 13:259-266.

(?) Zinn, Jacob, ANd Surface, F. M.

1917. STUDIES ON OAT BREEDING. V. THE $F_{1}$ AND $F_{2}$ GENERATIONS OF A CROSS BETWEEN A NAKED AND A HULLED OAT. Jour. Agr. Res., 10:293-312.

\section{APPENDIX}




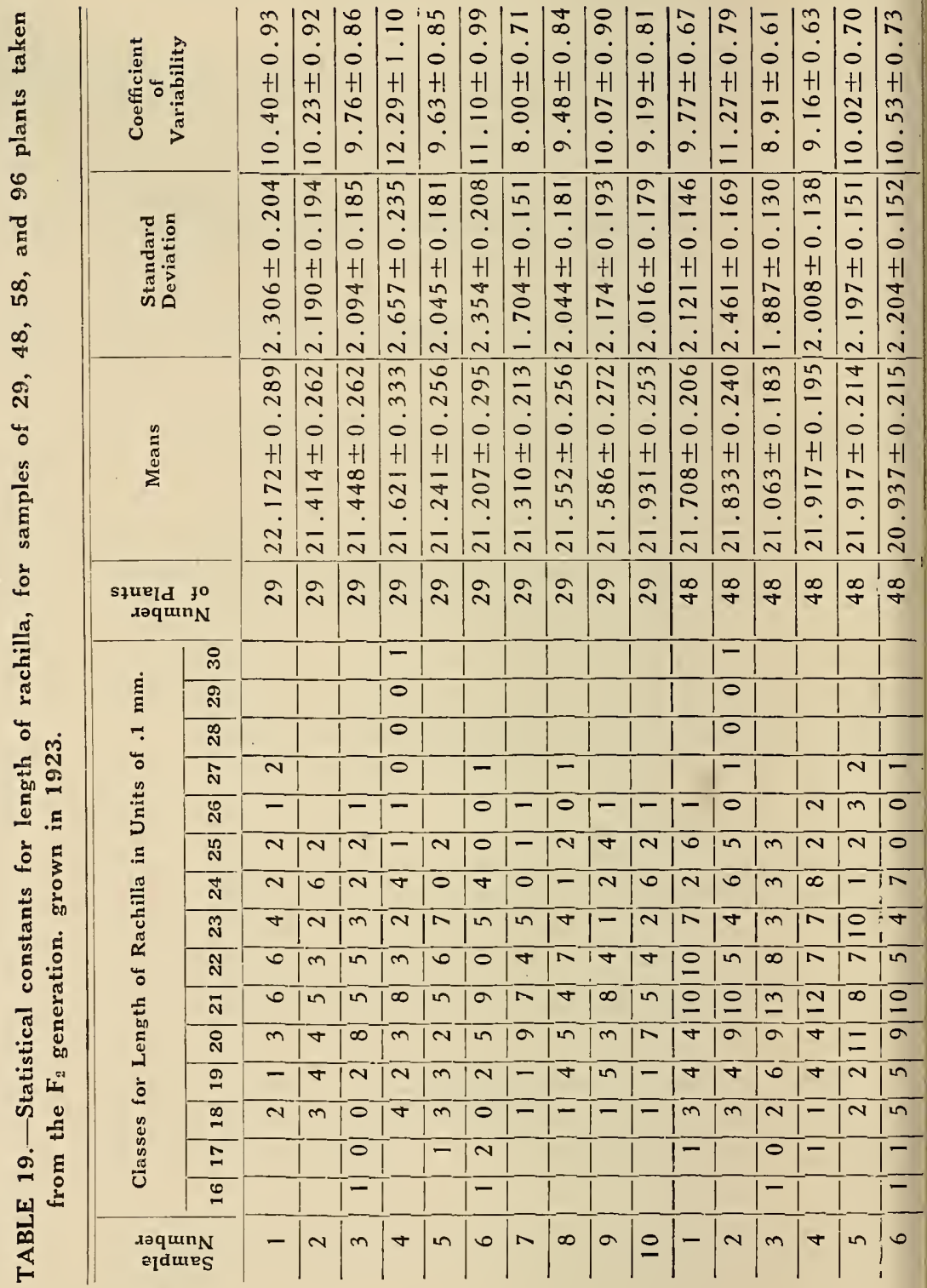




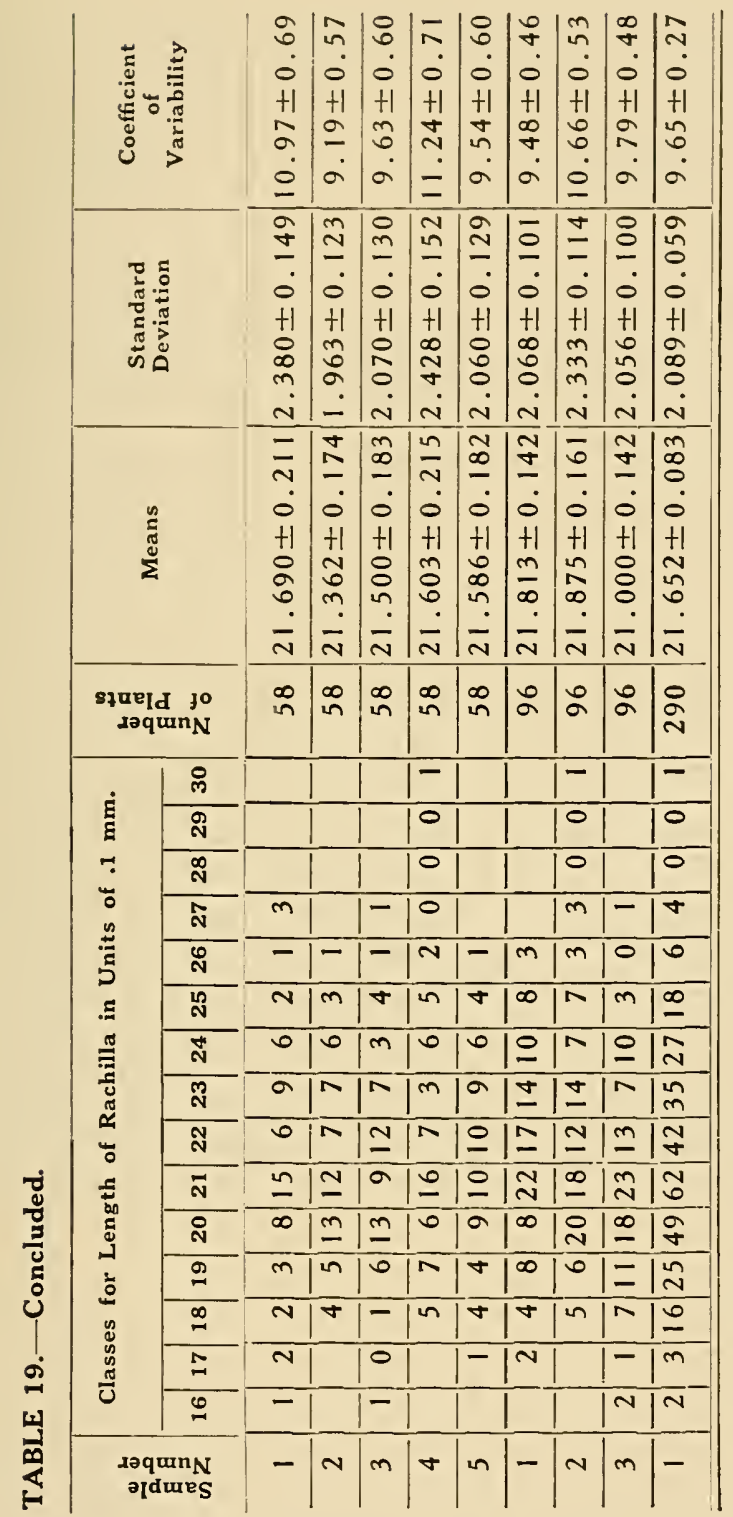


TABLE 20.- Statistical constants for length of rachilla of the Early Gothla parent grown in various plots in 1925.

\begin{tabular}{|c|c|c|c|c|c|c|c|c|c|c|}
\hline \multirow{2}{*}{$\begin{array}{c}1925 \\
\text { Row } \\
\text { Number }\end{array}$} & \multicolumn{6}{|c|}{$\begin{array}{l}\text { Classes for Length } \\
\text { of Rachilla in Units } \\
\text { of .1 mm. }\end{array}$} & \multirow{2}{*}{$\begin{array}{l}\dot{0} \\
z \\
\text { శี } \\
0 \\
1\end{array}$} & \multirow[t]{2}{*}{ Means } & \multirow{2}{*}{$\begin{array}{l}\text { Standard } \\
\text { Deviation }\end{array}$} & \multirow{2}{*}{$\begin{array}{l}\text { Coefficien } \\
\text { of } \\
\text { Variabilit }\end{array}$} \\
\hline & 25 & 26 & 27 & 28 & 29 & 30 & & & & \\
\hline $604-606$ & & 15 & 27 & 7 & 1 & & 50 & $26.880 \pm 0.068$ & $0.711 \pm 0.048$ & $2.64 \pm 0$. \\
\hline $625-627$ & 21 & 10 & 24 & $13 !$ & & 1 & 50 & $27.040 \pm$ & $0.894=$ & $3.31 \pm 0$ \\
\hline $648-650$ & 3 & 16 & 16 & 10 & & & $\overline{45}$ & $26.733 \pm 0.088$ & $0.879 \pm 0.062$ & $3.29 \pm 0$ \\
\hline $679-681$ & 6 & 17 & 20 & 7 & & & 50 & $26.560 \div 0.083$ & $0.875 \pm 0.059$ & $3.29 \pm 0$ \\
\hline $711-713$ & 3 & 12 & 24 & 10 & 1 & & $\mid 50$ & $26.880 \pm 0.082$ & $0.863 \pm 0.058$ & $3.21 \pm 0$ \\
\hline $745-747$ & $\overline{4}$ & $\overline{22}$ & 17 & 7 & & & $\overline{50}$ & $26.540 \pm 0.079$ & $0.830 \pm 0.056$ & $3.13 \pm 0$ \\
\hline 779 & & $\overline{17}$ & 23 & 7 & & & 47 & $26.787 \pm 0.067$ & $0.682 \pm 0.047$ & $2.55 \pm 0$ \\
\hline $808-810$ & 1 & 8 & 25 & 16 & & & 50 & $27.120 \pm 0.070$ & $0.739 \pm$ & $2.72 \pm 0$ \\
\hline $839-841$ & 4 & 15 & 21 & 7 & 1 & & $\overline{48}$ & $26.708 \pm 0.087$ & $\overline{0.889 \pm 0.061}$ & $3.33 \pm 0$ \\
\hline 75 & 3 & 13 & 23 & 11 & & & 50 & $26.840 \pm 0.079$ & $0.833 \pm 0.056$ & $3.10 \pm 0$ \\
\hline $905-907$ & 1 & $\overline{12}$ & 24 & $\overline{9}$ & 4 & & 50 & $27.060 \pm 0.086$ & $\overline{0.904 \pm 0.061}$ & $3.34 \pm 0$ \\
\hline $936-938$ & $\overline{1}$ & 10 & 25 & 11 & $\overline{1}$ & & 48 & $27.021 \pm 0.076$ & $0.777 \pm$ & $2.88 \pm 0$ \\
\hline $967-969$ & 2 & 8 & 27 & 12 & 1 & & 50 & $27.040 \pm 0.076$ & $0.799 \pm$ & $2.95 \pm 0$ \\
\hline $1003-1005$ & 4 & 14 & 22 & 6 & 1 & & 47 & $26.702 \pm 0.086$ & $0.673 \pm 0.061$ & $3.27 \pm 0$ \\
\hline$\overline{1035-1037}$ & $\overline{4}$ & 9 & 30 & $\overline{4}$ & & & $\overline{47}$ & $\overline{26.723 \pm 0.072}$ & $\overline{0.735 \pm 0.051}$ & $2.75 \pm 0$. \\
\hline $1061-1063$ & 2 & 7 & 26 & $\overline{14}$ & 1 & & 50 & $27.100 \pm 0.077$ & $\overline{0.806 \pm 0.054}$ & $2.97 \pm 0$ \\
\hline $1081-1083$ & 3 & 7 & 29 & 8 & 3 & & 50 & $27.020 \pm 0.084$ & $0.883 \pm 0.060$ & $3.27 \pm 0$ \\
\hline $1114-1116$ & 2 & 11 & 19 & 14 & 4 & & 50 & $27.140 \pm 0.093$ & $0.980 \pm 0.066$ & $3.61 \pm 0$ \\
\hline
\end{tabular}


1BLE 21.- Statistical constants for length of rachilla of the Garton 784 parent grown in various plots in 1925.

\begin{tabular}{|c|c|c|c|c|c|c|c|c|c|c|c|}
\hline \multirow{2}{*}{$\begin{array}{c}1925 \\
\text { Row } \\
\text { Number }\end{array}$} & \multicolumn{7}{|c|}{$\begin{array}{l}\text { Classes for Length } \\
\text { of Rachilla in Units } \\
\text { of } .1 \mathrm{~mm} \text {. }\end{array}$} & \multirow{2}{*}{$=\begin{array}{l}0 \\
z \\
0 \\
0 \\
0\end{array}$} & \multirow[t]{2}{*}{ Means } & \multirow{2}{*}{$\begin{array}{l}\text { Standard } \\
\text { Deviation }\end{array}$} & \multirow{2}{*}{$\begin{array}{c}\text { Coefficient } \\
\text { of } \\
\text { Variability }\end{array}$} \\
\hline & 14 & 15 & 16 & 1 & & 18 & 19 & & & & \\
\hline $607-609$ & & 3 & 24 & 20 & & 3 & & 50 & $16.460 \pm 0.067$ & $0.699 \pm 0.047$ & $4.25 \pm 0.29$ \\
\hline $628-630$ & & 2 & 26 & 2 & & 1 & & 50 & $16.420 \pm 0$ & $0.603 \pm$ & $3.67 \pm 0.25$ \\
\hline $651-653$ & & 3 & 34 & 13 & & & & 50 & $16.200 \pm 0.050$ & $0.529 \pm 0.036$ & $3.26 \pm 0.22$ \\
\hline $682-684$ & & 3 & 32 & 15 & & & & 50 & $16.240 \pm 0.052$ & $0.550 \pm$ & $3.39 \pm 0.23$ \\
\hline $7|4-7| 6$ & & 4 & 27 & 15 & & & & 50 & $16.300 \pm 0.058$ & $0.608 \pm$ & $3.73 \pm 0.25$ \\
\hline $784-750$ & & 15 & 29 & 5 & 5 & 0 & 1 & 50 & $15.860 \pm 0.071$ & $0.749 \pm 0$ & $4.72 \pm$ \\
\hline $782-784$ & & 5 & 27 & 15 & & 3 & & 50 & $16.320 \pm 0.070$ & $0.733 \pm 0.049$ & $4.49 \pm 0.30$ \\
\hline $811-813$ & & 9 & 31 & 10 & & & & 50 & $16.020 \pm 0.059$ & $0.616 \pm 0.042$ & $3.84 \pm$ \\
\hline $842-844$ & & 7 & 25 & 16 & & 2 & & 50 & $16.260 \pm 0.071$ & $0.743 \pm 0.050$ & $4.57 \pm 0.31$ \\
\hline $876-878$ & 1 & 5 & 24 & 18 & & 1 & & 49 & $16.265 \pm 0.072$ & $0.750 \pm 0.051$ & $4.61 \pm 0.31$ \\
\hline $908-910$ & & 3 & 24 & 18 & & 5 & & 50 & $16.500 \pm 0.072$ & $0.755 \pm 0.051$ & $4.58 \pm 0.31$ \\
\hline $939-941$ & & 5 & 31 & 1 & & 2 & & 50 & $16.220 \pm 0.064$ & $0.672 \pm 0$ & $4.14 \pm$ \\
\hline $970-972$ & & 14 & 26 & 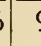 & 9 & 0 & 1 & 50 & $15.960 \pm 0.076$ & $0.799 \pm 0$ & $5.01=$ \\
\hline $06-1008$ & & 9 & 23 & 13 & & 2 & & 47 & $16.170 \pm 0.077$ & $0.780 \pm 0$ & $4.82 \pm 0.34$ \\
\hline $38-1040$ & & 8 & 30 & 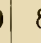 & 8 & 2 & & 48 & $16.083 \pm 0.068$ & $0.702 \pm 0.048$ & $4.36 \pm 0.30$ \\
\hline $64-1066$ & & 11 & 30 & ) & 8 & 1 & & 50 & $15.980 \pm 0.065$ & $0.678 \pm 0.046$ & $4.24 \pm 0.29$ \\
\hline $84-1086$ & & 4 & 3.3 & 13 & & & & 50 & $16.180 \pm 0.053$ & $0.555 \pm 0.037$ & $3.43 \pm 0.23$ \\
\hline 1 & & 7 & 21 & 2 & & 2 & & 50 & $16.340 \pm 0.073$ & $0.764 \pm 0.052$ & $4.68 \pm 0.31$ \\
\hline
\end{tabular}


이인

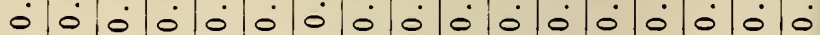
$+1+1+1+1+1+1+1+1+1+1+1+1+1+1+1+1$ ప

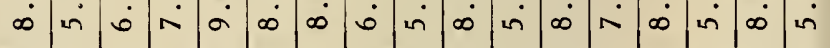

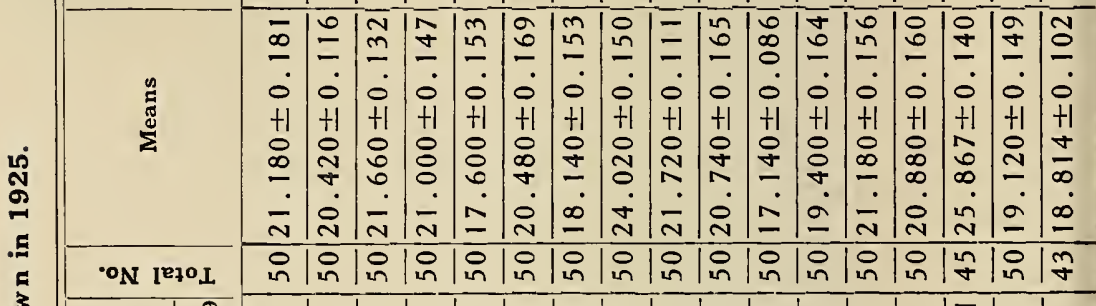

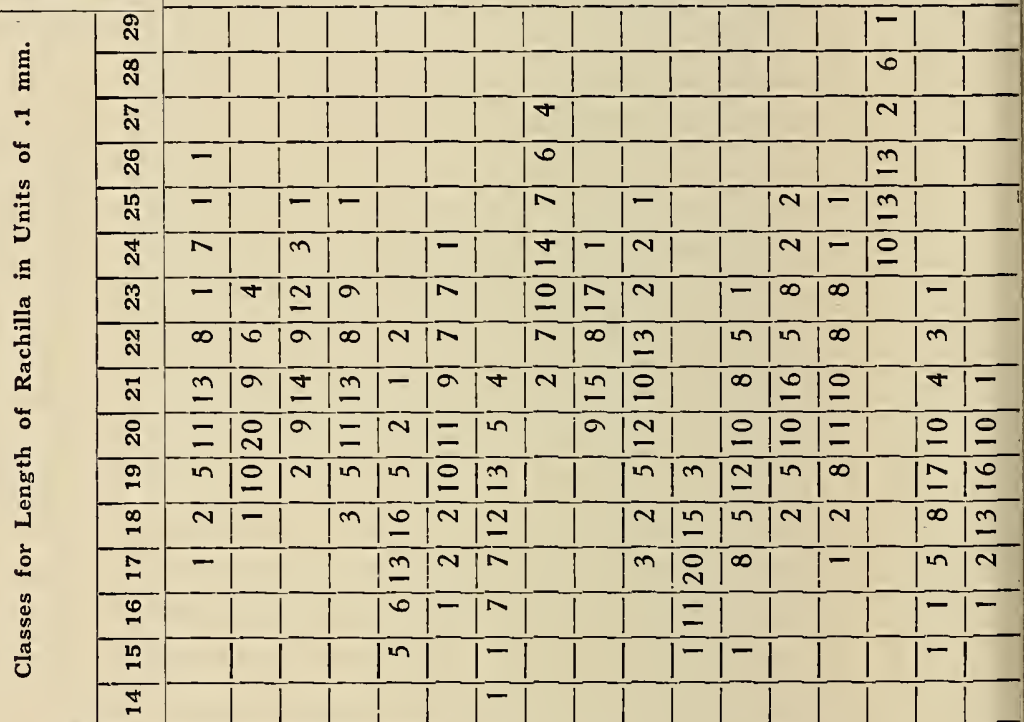

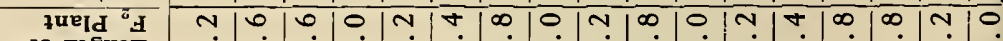

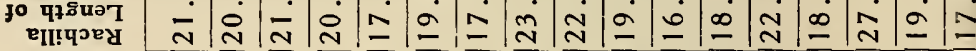
z n 过

ż

กิ

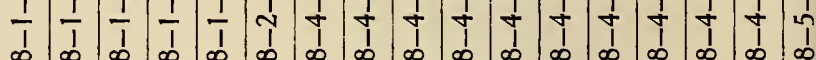

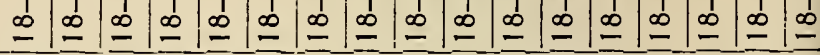

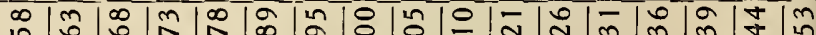
贻 


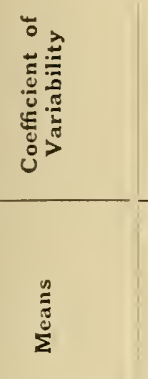

F

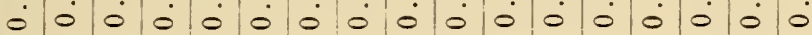
$+1+1+1+1+1+1+1+1+1+1+1+1+1+1+1+1+1$

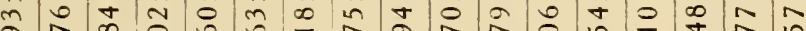

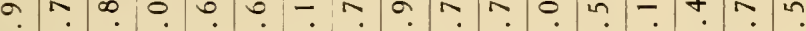

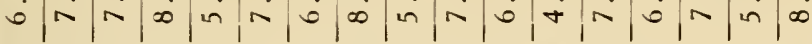
$m|m| \begin{aligned} & m \mid 0 \\ & m\end{aligned}$ - - - - - - - - - - - 0 - - - -

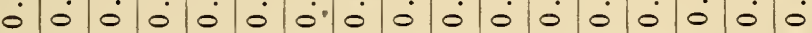
$+1+1+1+1+1+1+1+1+1+1+1+1+1+1+1+1$

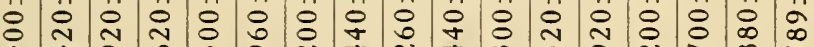

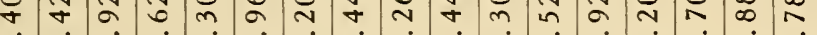

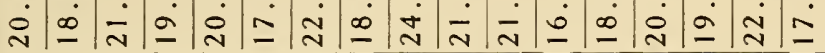

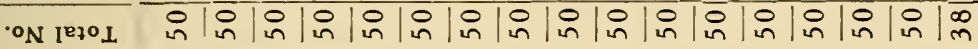

\begin{tabular}{|c|c|c|c|c|c|c|c|c|c|c|c|c|c|c|c|c|}
\hline ล & & & & & & & & & & & & & & & & \\
\hline$\stackrel{\infty}{N}$ & & & & & & & & & - & & & & & & & \\
\hline กิ & & & & & & & & & $N$ & & & & & & & \\
\hline$\stackrel{\leftrightarrow}{N}$ & & & 1 & & & & & & 0 & - & $1-$ & & & & $1-$ & \\
\hline ลี & & & $\sigma$ & & & & $m$ & & $\overline{=}$ & & $1-$ & & & & 10 & \\
\hline N & $N$ & & $\bar{N}$ & - & & & $n$ & & $\underline{0}$ & $\sigma$ & $N$ & & & & $\simeq$ & \\
\hline$\overline{\text { มู }}$ & $N$ & & $1=$ & IN & $1-$ & & 0 & & 음 & $a$ & $\sigma$ & & $N$ & IN & $\underline{m}$ & \\
\hline N & $m$ & - & $\underline{N}$ & $m$ & $\pi$ & & $\bar{v}$ & $m$ & $m$ & a & 10 & $N$ & N & $\sigma$ & $\underline{m}$ & \\
\hline$\overline{\vec{N}}$ & $\underline{0}$ & $v$ & 10 & 10 & $=$ & $v$ & $a$ & $v$ & & $I$ & 1 & 0 & a & 10 & in & $N$ \\
\hline
\end{tabular}

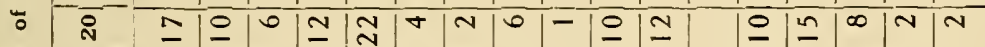

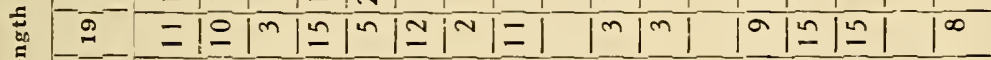
䍃

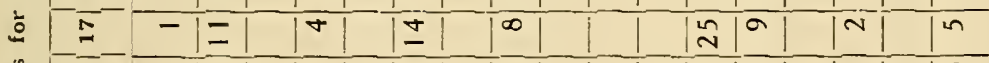

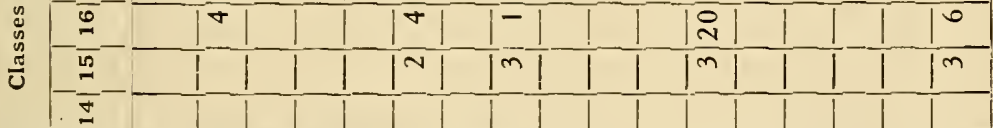

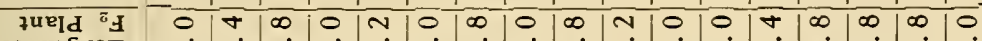

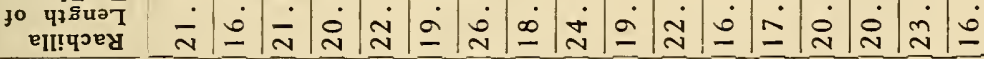

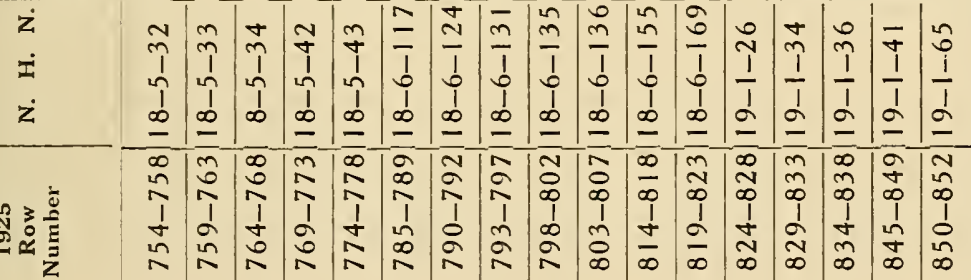




\begin{tabular}{|c|c|c|c|c|c|c|c|c|c|c|c|c|c|c|c|c|c|c|}
\hline \multicolumn{2}{|c|}{ 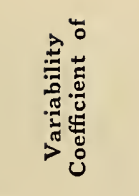 } & $\begin{array}{l}\stackrel{0}{q} \\
0 \\
0 \\
+1 \\
\infty \\
\infty \\
\text { in }\end{array}$ & $\begin{array}{l}\infty \\
m \\
0 \\
+1 \\
+1 \\
0 \\
\text { in }\end{array}$ & 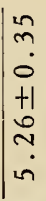 & $\mid \begin{array}{l}m \\
n \\
0 \\
+1 \\
+1 \\
0 \\
\infty \\
n\end{array}$ & $\begin{array}{l}0 \\
\sim \\
0 \\
+1 \\
n \\
m \\
n\end{array}$ & $\begin{array}{l}0 \\
\infty \\
0 \\
+1 \\
+1 \\
\tilde{0} \\
0 \\
0\end{array}$ & $\mid \begin{array}{c}\infty \\
m \\
0 \\
+1 \\
0 \\
0 \\
0 \\
n\end{array}$ & $\mid \begin{array}{l}0 \\
0 \\
0 \\
+1 \\
\sigma \\
\sigma \\
\text { ज. }\end{array}$ & 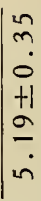 & $\begin{array}{l}\infty \\
m \\
0 \\
+1 \\
\frac{1}{n} \\
\dot{n}\end{array}$ & $\begin{array}{l}\infty \\
\sim \\
0 \\
+1 \\
\frac{1}{\sim} \\
\dot{\sim}\end{array}$ & $\mid \begin{array}{l}0 \\
9 \\
0 \\
+1 \\
0 \\
0 \\
\pm \\
\pm\end{array}$ & $\begin{array}{l}0 \\
m \\
0 \\
+1 \\
0 \\
0 \\
\dot{1} \\
\dot{0}\end{array}$ & $\begin{array}{l}\sigma \\
m \\
0 \\
+1 \\
2 \\
a \\
\vdots \\
\dot{\sigma}\end{array}$ & $\begin{array}{c}0 \\
n \\
0 \\
+1 \\
2 \\
a \\
n\end{array}$ & $\left\{\begin{array}{l}\sim \\
\sigma \\
0 \\
+1 \\
\dot{v} \\
v \\
0\end{array}\right.$ & $\begin{array}{l}0 \\
+ \\
0 \\
+1 \\
0 \\
0 \\
1 \\
0\end{array}$ \\
\hline \multicolumn{2}{|c|}{ 营 } & 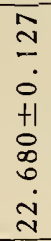 & $\mid \begin{array}{l}0 \\
= \\
0 \\
+1 \\
0 \\
0 \\
0 \\
- \\
-\end{array}$ & $\mid$\begin{tabular}{l}
$\bar{I}$ \\
$\simeq$ \\
0 \\
0 \\
+1 \\
0 \\
0 \\
\hdashline \\
$\dot{v}$ \\
$v$
\end{tabular} & {$\left[\begin{array}{c}0 \\
0 \\
0 \\
0 \\
+1 \\
0 \\
0 \\
0 \\
0 \\
\sim \\
N\end{array}\right.$} & $\begin{array}{l}0 \\
m \\
\\
0 \\
+1 \\
0 \\
0 \\
0 \\
+ \\
\infty \\
0\end{array}$ & $\mid \begin{array}{c}0 \\
0 \\
\sim \\
0 \\
0 \\
+1 \\
0 \\
0 \\
\infty \\
\text { v } \\
\sim \\
v\end{array}$ & 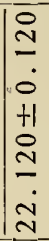 & 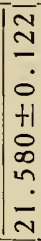 & 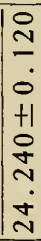 & 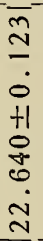 & $\begin{array}{l}\infty \\
\infty \\
0 \\
0 \\
0 \\
0 \\
+1 \\
0 \\
0 \\
0 \\
0 \\
\sim \\
\sim\end{array}$ & 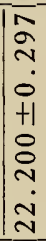 & 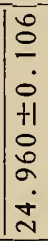 & 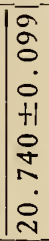 & in & \begin{tabular}{l}
$m$ \\
$m$ \\
\hdashline \\
0 \\
+1 \\
0 \\
0 \\
$m$ \\
$\sim$ \\
$\sim$ \\
$\sim$
\end{tabular} & $\begin{array}{l}m \\
\pm \\
\dot{I} \\
0 \\
+1 \\
0 \\
0 \\
\underline{0} \\
\tilde{N}\end{array}$ \\
\hline \multicolumn{2}{|c|}{$0^{\circ} 1^{e \nmid o} L$} & 요 & 10 & 10 & 10 & 10 & 19 & 10 & 10 & 10 & in & io & ion & io & 18 & i응 & |유 & 10 \\
\hline \multirow{3}{*}{ घं } & ล & & & & & & & & & - & & & $1-$ & & & & & \\
\hline & N & & & & & & & & & & & & $m$ & & & & & \\
\hline & $\hat{N}$ & & & 12 & & & & & & $m$ & & & 1 & $\ln$ & & & & \\
\hline \multirow{3}{*}{$\begin{array}{l}-1 \\
\vdots \\
0 \\
\vdots \\
5\end{array}$} & $\stackrel{\mathscr{N}}{\mathrm{N}}$ & $=$ & & $\infty$ & & & - & & & $=$ & - & & - & $1=$ & & 1 & & \\
\hline & ก & - & & $\pi$ & 7 & & - & $m$ & & $1=$ & - & & & 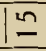 & & & $m$ & 10 \\
\hline & N & $\underline{m}$ & $m$ & $1 \pm$ & $n$ & & $m$ & $\pi$ & in & 19 & $m$ & iv & & $1 \stackrel{2}{-}$ & & in & a & IN \\
\hline \multirow{3}{*}{ 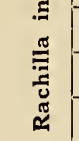 } & Мू & $\underline{m}$ & $1 m$ & $1 \pm$ & 10 & & $m$ & 10 & $\infty$ & $1 \cong$ & $=$ & $1 \pm$ & $m$ & $\sigma$ & iv & I & 10 & 10 \\
\hline & ลิ & \pm & $1 m$ & $\bar{N}$ & $n$ & - & $m$ & 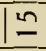 & 19 & & $1 \pm$ & 10 & \% & & $1=$ & 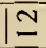 & 12 & $m$ \\
\hline & $\overline{\mathrm{N}}$ & $n$ & $1 \pm$ & & $1 \cong$ & $m$ & 1 & $1 \stackrel{2}{2}$ & $1 \infty$ & & $\infty$ & 1 & \pm & & $1 \pm$ & 10 & 10 & $1 \pm$ \\
\hline \multirow{7}{*}{ 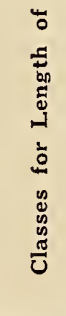 } & ลิ & v & in & & 0 & $\infty$ & & $m$ & 1a & & $\sqrt{v}$ & 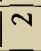 & $1=$ & & $1 \infty$ & $\infty$ & $m$ & in \\
\hline & 2 & - & iv & & $\sigma$ & $\infty$ & & & $1-$ & & & & $\sigma$ & & in & $1 \stackrel{m}{=}$ & - & $1-$ \\
\hline & $\stackrel{\infty}{\sim}$ & & & & & 19 & & & & & & & $1=$ & & & $1=$ & & \\
\hline & \pm & & & & & $\infty$ & & & & & & & T- & & & & & \\
\hline & $\because$ & & & & & $m$ & & & & & & & & & & & & \\
\hline & $\stackrel{25}{2}$ & & & & & & & & & & & & & & & & & \\
\hline & $\bar{\Delta}$ & & & & & & & & & & & & & & & & & \\
\hline \multicolumn{2}{|c|}{ 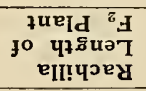 } & $\begin{array}{l}0 \\
v \\
v\end{array}$ & i⿱亠凶禸 & in & $\frac{v}{2}$ & 10 & $\stackrel{\infty}{\infty}$ & $\stackrel{v}{i}$ & {$\left[\begin{array}{l}\dot{v} \\
\text { in } \\
\right.$\cline { 1 - 1 }\end{array}} & $\mid \begin{array}{l}\infty \\
\dot{\pi} \\
0\end{array}$ & $\bar{\square}$ & $\begin{array}{l}\infty \\
\\
\end{array}$ & a & in & $\bar{\pi}$ & i & in & in \\
\hline \multicolumn{2}{|c|}{$\begin{array}{l}\dot{z} \\
\dot{z} \\
\dot{z}\end{array}$} & $\begin{array}{l}N \\
\Upsilon 1 \\
\\
0\end{array}$ & $\begin{array}{l}\infty \\
\uparrow \\
1 \\
\eta \\
1 \\
\underline{1}\end{array}$ & $\begin{array}{l}a \\
\dot{1} \\
1 \\
1 \\
a\end{array}$ & $\begin{array}{l}n \\
n \\
1 \\
n \\
1 \\
a\end{array}$ & $\begin{array}{l}\overline{0} \\
1 \\
0 \\
1 \\
a \\
0\end{array}$ & $\begin{array}{c}\pi \\
1 \\
j \\
\vdots \\
0\end{array}$ & $\begin{array}{l}0 \\
1 \\
1 \\
1 \\
0 \\
-1\end{array}$ & $\begin{array}{l}2 \\
n \\
1 \\
\vdots \\
1 \\
0 \\
=\end{array}$ & $\begin{array}{l}\infty \\
\infty \\
1 \\
1 \\
1 \\
1 \\
0\end{array}$ & $\begin{array}{l}a \\
\infty \\
1 \\
1 \\
1 \\
0 \\
0\end{array}$ & $\begin{array}{l}5 \\
\vdots \\
1 \\
\vdots \\
1 \\
0 \\
-\end{array}$ & $\begin{array}{l}m \\
1 \\
1 \\
1 \\
0 \\
0\end{array}$ & $\begin{array}{l}\frac{n}{1} \\
1 \\
1 \\
0 \\
0\end{array}$ & $\begin{array}{l}0 \\
1 \\
1 \\
1 \\
0 \\
-1\end{array}$ & $\begin{array}{l}1 \\
1 \\
1 \\
1 \\
0\end{array}$ & $\begin{array}{l}\mathfrak{n} \\
\mathfrak{1} \\
\mathfrak{1} \\
1 \\
a\end{array}$ & $\begin{array}{l}m \\
n \\
1 \\
1 \\
1 \\
0\end{array}$ \\
\hline \multicolumn{2}{|c|}{ 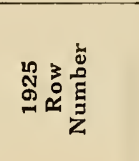 } & $\begin{array}{l}n \\
\infty \\
1 \\
1 \\
n \\
\infty \\
\infty\end{array}$ & $\mid \begin{array}{l}N \\
\infty \\
\infty \\
1 \\
\infty \\
n \\
\infty\end{array}$ & $\mid \begin{array}{l}0 \\
0 \\
\infty \\
1 \\
0 \\
\infty\end{array}$ & $\mid \begin{array}{l}N \\
\infty \\
\infty \\
1 \\
\infty \\
0 \\
\infty\end{array}$ & $\mid \begin{array}{l}m \\
\infty \\
\infty \\
1 \\
0 \\
\infty \\
\infty\end{array}$ & $\underset{\infty}{+}$ & $\begin{array}{l}2 \\
\infty \\
\infty \\
1 \\
1 \\
\infty \\
\infty\end{array}$ & $\mid \begin{array}{l}0 \\
2 \\
\infty \\
1 \\
1 \\
0 \\
0 \\
\infty\end{array}$ & $\begin{array}{l}2 \\
2 \\
\infty \\
1 \\
2 \\
2 \\
\infty\end{array}$ & $\begin{array}{l}5 \\
0 \\
0 \\
1 \\
8 \\
0 \\
0\end{array}$ & $\frac{\frac{1}{a}}{\frac{1}{a}}$ & 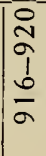 & $\frac{\tilde{\sigma}}{\tilde{\gamma}}$ & $\begin{array}{l}0 \\
\text { an } \\
\mathfrak{j} \\
\text { va } \\
\alpha\end{array}$ & $\frac{\hat{q}}{n}$ & $\mid \begin{array}{c}0 \\
\vdots \\
a \\
1 \\
v \\
j \\
a\end{array}$ & $\mid \begin{array}{l}\bar{n} \\
a \\
1 \\
5 \\
5\end{array}$ \\
\hline
\end{tabular}




\begin{tabular}{|c|c|c|c|c|c|c|c|c|c|c|}
\hline $\mathbb{E}_{0}$ & & $\begin{array}{l}a \\
\dot{v} \\
0 \\
+1 \\
\sim \\
\stackrel{n}{n}\end{array}$ & $\begin{array}{l}\bar{J} \\
\dot{0} \\
+1 \\
\stackrel{1}{1} \\
\dot{0}\end{array}$ & $\begin{array}{l}n \\
\dot{\sigma} \\
0 \\
+1 \\
\sim \\
\sim \\
0\end{array}$ & $\begin{array}{c}+ \\
m \\
0 \\
+1 \\
v \\
0 \\
\dot{n}\end{array}$ & $\begin{array}{l}n \\
n \\
0 \\
+1 \\
m \\
0 \\
\infty\end{array}$ & $\begin{array}{l}m \\
\dot{m} \\
0 \\
+1 \\
\infty \\
\dot{v} \\
\text { in }\end{array}$ & $\begin{array}{c}N \\
m \\
0 \\
+1 \\
\tilde{r} \\
\tilde{\sigma} \\
\dot{\sigma}\end{array}$ & $\begin{array}{l}0 \\
\text { v } \\
0 \\
+1 \\
n \\
m \\
\dot{+}\end{array}$ & $\begin{array}{l}0 \\
\dot{y} \\
0 \\
+1 \\
\sigma \\
\sigma \\
\text { in }\end{array}$ \\
\hline \multicolumn{2}{|c|}{ 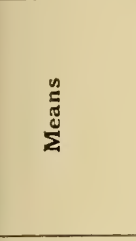 } & $\begin{array}{c}- \\
I \\
0 \\
+1 \\
0 \\
0 \\
+ \\
\dot{v}\end{array}$ & \begin{tabular}{l}
$\bar{m}$ \\
\hdashline \\
0 \\
+1 \\
0 \\
$\sim$ \\
$\vec{v}$ \\
$\stackrel{v}{v}$
\end{tabular} & $\begin{array}{l}n \\
m \\
0 \\
0 \\
+1 \\
0 \\
0 \\
0 \\
0 \\
0 \\
\sim\end{array}$ & $\begin{array}{l}0 \\
0 \\
0 \\
0 \\
+1 \\
0 \\
+ \\
\infty \\
0 \\
0\end{array}$ & \begin{tabular}{l}
0 \\
$n$ \\
\hdashline \\
0 \\
+1 \\
0 \\
0 \\
$m$ \\
0 \\
0 \\
0
\end{tabular} & $\begin{array}{l}0 \\
= \\
0 \\
+1 \\
0 \\
0 \\
\vdots \\
0 \\
0\end{array}$ & $\mid \begin{array}{l}0 \\
0 \\
0 \\
0 \\
H \\
1 \\
0 \\
0 \\
+ \\
-1 \\
-1\end{array}$ & $\mid \begin{array}{l}0 \\
0 \\
0 \\
0 \\
+1 \\
0 \\
0 \\
2 \\
2 \\
\sim \\
v\end{array}$ & 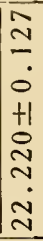 \\
\hline \multicolumn{2}{|c|}{$\left.{ }^{\circ} \mathrm{N}\right]^{e}+0_{1}$} & 은 & 옷 & 은 & in & I용 & in & in & 1은 & i요 \\
\hline \multirow{3}{*}{ घं } & ลิ & $N$ & & & & & & & & \\
\hline & in & $N$ & & & & & & & $N$ & \\
\hline & N & $N$ & & & & & & & $a$ & \\
\hline \multirow{3}{*}{$\begin{array}{l} \pm \\
5 \\
5 \\
5 \\
5 \\
5\end{array}$} & \& & $N$ & & & & & & & $m$ & \\
\hline & ง & $a$ & $N$ & & & $1-$ & & & $1 \infty$ & $\bar{v}$ \\
\hline & N & 01 & $=$ & - & - & - & & & 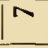 & $\pi$ \\
\hline \multirow{3}{*}{ 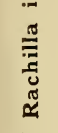 } & जু & \pm 1 & $\underline{-}$ & 0 & $m$ & $m$ & $\nabla$ & $\pi$ & $1-$ & $1 \pm$ \\
\hline & N & $m$ & $\infty$ & $\simeq$ & 0 & in & $1 m$ & $\underline{\underline{N}}$ & & $m$ \\
\hline & $\overline{\text { ลี }}$ & - & $\cong$ & \pm & 오 & 12 & 101 & $1 \pm$ & & $1 \cong$ \\
\hline \multirow{7}{*}{ 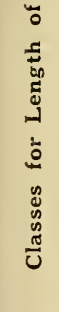 } & ำ & & $\nabla$ & 6 & I & $1 \pm$ & $1 \geq$ & $\pi$ & & $m$ \\
\hline & 2 & & & 10 & $m$ & 10 & $\nabla$ & $N$ & & $1-$ \\
\hline & $\stackrel{\infty}{\sim}$ & & & - & & $m$ & $1=$ & & & \\
\hline & $\approx$ & & & & & $N$ & & & & \\
\hline & $\stackrel{2}{2}$ & & & & & & & & & \\
\hline & 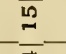 & & & & & & & & & \\
\hline & \pm & & & & & & & & & \\
\hline \multicolumn{2}{|c|}{ 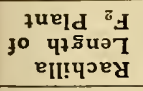 } & $\begin{array}{l}\infty \\
\dot{0} \\
\sim\end{array}$ & $\stackrel{v}{\sim}$ & $\begin{array}{l}0 \\
0 \\
0\end{array}$ & 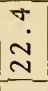 & 冓 & $\mid \begin{array}{l}0 \\
0 \\
0 \\
1\end{array}$ & $\frac{0}{2}$ & {$\left[\begin{array}{l}0 \\
\ddot{v} \\
i\end{array}\right.$} & $\begin{array}{l}0 \\
\ddot{v} \\
\tilde{N}\end{array}$ \\
\hline \multicolumn{2}{|c|}{$\begin{array}{l}\dot{z} \\
\dot{z} \\
\dot{z}\end{array}$} & $\begin{array}{l}n \\
n \\
1 \\
a \\
1 \\
a \\
-\end{array}$ & $\begin{array}{l}0 \\
m \\
1 \\
1 \\
1 \\
0 \\
=\end{array}$ & $\begin{array}{l}\infty \\
0 \\
1 \\
n \\
1 \\
0 \\
-1\end{array}$ & $\begin{array}{l}\bar{y} \\
1 \\
0 \\
1 \\
0 \\
-\end{array}$ & $\mid \begin{array}{l}a \\
1 \\
1 \\
1 \\
0 \\
-\end{array}$ & $\begin{array}{l}n \\
m \\
1 \\
0 \\
1 \\
a \\
-\end{array}$ & $\begin{array}{l}m \\
m \\
b \\
1 \\
a \\
=\end{array}$ & $\begin{array}{l}0 \\
0 \\
1 \\
1 \\
1 \\
0 \\
=\end{array}$ & $\begin{array}{l}-5 \\
1 \\
0 \\
1 \\
0 \\
0\end{array}$ \\
\hline \multicolumn{2}{|c|}{ 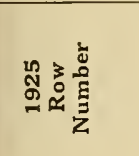 } & $\begin{array}{l}0 \\
2 \\
a \\
1 \\
N \\
2 \\
a\end{array}$ & $\mid \begin{array}{l}1 \\
0 \\
1 \\
1 \\
n \\
a \\
\end{array}$ & $\mid \begin{array}{l}0 \\
0 \\
0 \\
1 \\
1 \\
0 \\
0\end{array}$ & $\left|\begin{array}{l}a \\
a \\
i \\
m \\
a \\
a\end{array}\right|$ & $\mid \begin{array}{l}1 \\
\infty \\
a \\
1 \\
\infty \\
1 \\
a\end{array}$ & $\mid \begin{array}{l}\infty \\
\infty \\
a \\
1 \\
m \\
\infty \\
\alpha\end{array}$ & $\begin{array}{l}n \\
\alpha \\
\alpha \\
1 \\
\infty \\
\infty \\
a\end{array}$ & $\begin{array}{l}a \\
a \\
a \\
m \\
a \\
a\end{array}$ & $\mid \begin{array}{l}1 \\
0 \\
0 \\
1 \\
0 \\
2 \\
\alpha\end{array}$ \\
\hline
\end{tabular}


TABLE 23.-Breeding behavior of $F_{3}$ progenies for ligule, panicle type, grain c and rachilla pubescence.

\begin{tabular}{|c|c|c|c|c|c|c|c|c|c|c|c|c|c|c|c|}
\hline \multirow{3}{*}{$\begin{array}{c}1925 \\
\text { Row } \\
\text { Number }\end{array}$} & \multirow{3}{*}{ N. H. $\mathbf{N}$} & \multicolumn{3}{|c|}{ Ligule } & \multicolumn{3}{|c|}{ Panicle Type } & \multicolumn{4}{|c|}{ Grain Color } & \multicolumn{4}{|c|}{ Rachilla Pubescenc } \\
\hline & & \multirow{2}{*}{ ज्ञ } & \multicolumn{2}{|c|}{ 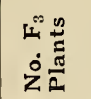 } & \multirow{2}{*}{ 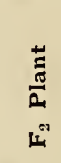 } & \multicolumn{2}{|c|}{ 望兽 } & \multirow{2}{*}{ 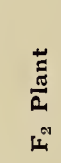 } & \multicolumn{3}{|c|}{$\underset{\text { Families }}{\mathbf{F}_{3}}$} & \multirow{2}{*}{ 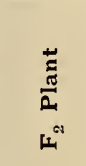 } & \multicolumn{3}{|c|}{$\underset{\text { Families }}{F_{3}}$} \\
\hline & & & $\mathbf{P}$ & $\mathbf{A}$ & & o & $\mathbf{S}$ & & $\infty$ & $\begin{array}{l}\dot{80} \\
\dot{0} \\
\dot{n}\end{array}$ & 3 & & हี่ & ஜ் & 7 \\
\hline $654-658$ & $18-1-25$ & $\mathrm{P}$ & 85 & & $\mathrm{O}$ & 85 & & B & & $\mathrm{x}$ & & Sm. & & $\mathrm{x}$ & \\
\hline $659-663$ & $18-1-29$ & $\mathrm{P}$ & 83 & 7 & $\mathrm{O}$ & 63 & 27 & B & & $\mathrm{x}$ & & Sm. & $\mathrm{x}$ & & \\
\hline $664-668$ & $18-1-32$ & $\mathrm{P}$ & 64 & 18 & $\mathrm{~S}$ & & 82 & B & & $\mathrm{x}$ & & Sm. & & $\mathrm{x}$ & \\
\hline $669-673$ & $18-1-66$ & A & & 86 & $\mathrm{~S}$ & & 86 & B & & $\mathrm{x}$ & & Sm. & & $\mathrm{x}$ & \\
\hline $674-678$ & $18-1-70$ & $\mathrm{P}$ & 58 & 16 & $\mathrm{O}$ & 41 & 33 & B & & $\mathrm{x}$ & & Sm. & & $\mathrm{x}$ & \\
\hline $685-689$ & $18-2-29$ & $\mathrm{P}$ & 86 & & $\mathrm{O}$ & 69 & 17 & W & & & $\mathrm{x}$ & Sm. & & $\mathrm{x}$ & \\
\hline $69 I-695$ & $18-4-22$ & $\mathrm{P}$ & 59 & 25 & $\mathrm{~S}$ & & 84 & W & & & $\mathrm{x}$ & Sm. & $\mathrm{x}$ & & \\
\hline $696-700$ & $18-4-42$ & $\mathrm{P}$ & & 85 & $\mathrm{O}$ & 66 & 19 & B & $\mathrm{x}$ & & & $\mathrm{H}$ & & & \\
\hline $701-705$ & $18-4-47$ & $\mathrm{P}$ & 63 & 26 & $S$ & & 89 & W & & & $\mathrm{x}$ & Sm. & & $\mathrm{x}$ & \\
\hline $706-710$ & $18-4-54$ & A & & 79 & $\mathrm{~S}$ & & 79 & B & $x$ & & & Sm. & & $\mathrm{x}$ & \\
\hline $717-721$ & $18-4-56$ & $\mathrm{P}$ & 73 & 7 & $\mathrm{O}$ & 49 & 31 & B & $\mathrm{x}$ & & & Sm. & $x$ & & \\
\hline $722-726$ & $18-4-58$ & $\mathrm{P}$ & 65 & 21 & $\mathrm{~S}$ & & 86 & B & $\mathrm{x}$ & & & Sm. & & $\mathrm{x}$ & \\
\hline $727-731$ & $18-4-68$ & $\mathrm{~A}$ & & 82 & $\mathrm{~S}$ & & 82 & W & & & $\mathrm{x}$ & Sm. & & $\mathrm{x}$ & \\
\hline $732-736$ & $18-4-76$ & $\mathrm{P}$ & 63 & 19 & $\mathrm{~S}$ & & 82 & W & & & $\mathrm{x}$ & Sm. & & $\mathrm{x}$ & \\
\hline $737-739$ & $18-4-77$ & $\mathrm{P}$ & 35 & 11 & $\mathrm{~S}$ & & 46 & W & & & $\mathrm{x}$ & $\mathrm{H}$ & & & $x$ \\
\hline $740-744$ & $\mid 18-4-104$ & $\mathrm{P}$ & 60 & 19 & $\mathrm{~S}$ & & 79 & B & & $\mathrm{x}$ & & Sm. & $x$ & & \\
\hline $751-753$ & $18-5-31$ & $\mathrm{P}$ & 34 & 11 & $\mathrm{~S}$ & & 45 & B & & $\mathrm{x}$ & & $\mathrm{H}$ & & $\mathrm{x}$ & \\
\hline $754-758$ & $18-5-32$ & A & & 90 & $\mathrm{~S}$ & & 90 & W & & & $\mathrm{x}$ & Sm. & & $\mathrm{x}$ & \\
\hline $759-763$ & $18-5-33$ & $\mathrm{P}$ & 79 & & $\mathrm{O}$ & 79 & & B & & $\mathrm{x}$ & & Sm. & & $\mathrm{x}$ & \\
\hline $764-768$ & $18-5-34$ & $\mathrm{P}$ & 71 & 18 & $\mathrm{~S}$ & & 89 & W & & & $\mathrm{x}$ & Sm. & & $\mathrm{x}$ & \\
\hline $769-733$ & $18-5-42$ & $P$ & 71 & & S & & 71 & B & & $\mathrm{x}$ & & Sm. & & $\mathrm{x}$ & \\
\hline
\end{tabular}

(Continued)

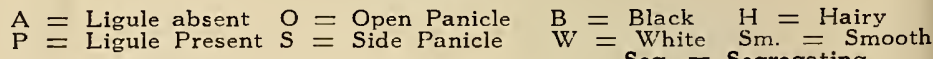
Seg. $=$ Segregating 
LE 23.-Continued.

\begin{tabular}{|c|c|c|c|c|c|c|c|c|c|c|c|c|c|c|c|c|}
\hline \multirow{3}{*}{ ber } & \multirow{3}{*}{ N. H. N. } & \multicolumn{3}{|c|}{ Ligule } & \multicolumn{3}{|c|}{ Panicle Type } & \multicolumn{4}{|c|}{ Grain Color } & \multicolumn{4}{|c|}{ Rachilla Pubescence } & \multirow{3}{*}{$\begin{array}{l}5 \\
z \\
0 \\
0 \\
0\end{array}$} \\
\hline & & \multirow{2}{*}{ 泀 } & \multicolumn{2}{|c|}{ 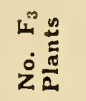 } & \multirow{2}{*}{$\frac{\vec{E}}{\vec{E}}$} & \multicolumn{2}{|c|}{ 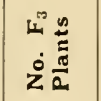 } & \multirow{2}{*}{ L" } & \multicolumn{3}{|c|}{$\begin{array}{c}F_{3} \\
\text { Families }\end{array}$} & \multirow{2}{*}{$\stackrel{\Xi}{\square}$} & \multicolumn{3}{|c|}{$\underset{\text { Families }}{\mathbf{F}_{3}}$} & \\
\hline & & & $\mathbf{P}$ & A & & 0 & s & & $\infty$ & 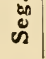 & 3 & & हี่ & $\ddot{\circ}$ & $\approx$ & \\
\hline-778 & $18-5-43$ & A & & 80 & S & & 80 & B & & $\mathrm{x}$ & & $\mathrm{Sm}$. & $x$ & & & 80 \\
\hline-789 & $\mid 8-6-117$ & A & & 91 & S & & 91 & B & & $\mathrm{x}$ & & Sm. & $\mathrm{x}$ & & & 91 \\
\hline-792 & $|8-6-124|$ & $\mathrm{P}$ & & 50 & $\mathrm{O}$ & 28 & 22 & W & & & $\mathrm{x}$ & $\mathrm{H}$ & & & $\mathrm{x}$ & 50 \\
\hline-797 & $18-6-131$ & A & & 77 & $S$ & & 77 & B & & $\mathrm{x}$ & & $\mathrm{Sm}$. & $\mathrm{x}$ & & & 77 \\
\hline-802 & $18-6-135$ & A & & 83 & $\mathrm{~S}$ & & 83 & W & & & $\mathrm{x}$ & $\mathrm{Sm}$ & & $\mathrm{x}$ & & 83 \\
\hline-807 & $18-6-136$ & A & & 88 & $\mathrm{~S}$ & & 88 & B & $\mathrm{x}$ & & & Sm. & & $\mathrm{x}$ & & 88 \\
\hline-818 & $18-6-155$ & $P$ & 73 & 18 & S & & 91 & B & $\mathrm{x}$ & & & $\mathrm{H}$ & & & $\mathrm{x}$ & 91 \\
\hline$|-823|$ & $|18-6-169|$ & $P$ & 80 & & $\mathrm{O}$ & 80 & & B & $\mathrm{x}$ & & & Sm. & $\mathrm{x}$ & & & 80 \\
\hline-828 & $19-1-26$ & $\mathrm{P}$ & 70 & 15 & $S$ & & 85 & B & & $\mathrm{x}$ & & Sm. & $x$ & & & 85 \\
\hline-833 & $19-1-34$ & $\mathrm{P}$ & 60 & 18 & $S$ & & 78 & B & & $\mathrm{x}$ & & Sm. & & $\mathrm{x}$ & & 78 \\
\hline-838 & $19-1-36$ & $P$ & 84 & & $\mathrm{O}$ & 84 & & B & & $\mathrm{x}$ & & $\mathrm{H}$ & & & $x$ & 84 \\
\hline-849 & $19-1-41$ & A & & 89 & $S$ & 89 & & W & & & $\mathrm{x}$ & $\mathrm{Sm}$ & $\mathrm{x}$ & & & 89 \\
\hline-852 & $19-1-65$ & $\mathrm{P}$ & 41 & & $\mathrm{O}$ & 41 & & B & & $\mathrm{x}$ & & Sm. & & $\mathrm{x}$ & & 41 \\
\hline-857 & $19-3-22$ & $\mathrm{P}$ & 59 & 25 & $\mathrm{~S}$ & & 84 & B & & $\mathrm{x}$ & & $\mathrm{H}$ & & & $\mathrm{x}$ & 84 \\
\hline-862 & $19-3-28$ & $\mathrm{P}$ & 89 & & $\mathrm{O}$ & 89 & & W & & & $\mathrm{x}$ & Sm. & $\mathrm{x}$ & & & 89 \\
\hline-867 & $19-3-49$ & $\mathrm{P}$ & $\overline{52}$ & 23 & $\mathrm{~S}$ & & 85 & B & $\mathrm{x}$ & & & $\mathrm{Sm}$. & & $\mathrm{x}$ & & 85 \\
\hline-872 & $19-3-55$ & A & & 87 & $\mathrm{~S}$ & & 87 & B & $\mathrm{x}$ & & & Sm. & & $\mathrm{x}$ & & 87 \\
\hline-883 & $19-3-61$ & A & & 76 & $S$ & & 76 & B & & $\mathrm{x}$ & & $\mathrm{Sm}$ & $x$ & & & 76 \\
\hline & $19-4-27$ & $\mathrm{P}$ & 15 & & 0 & & 15 & B & & $\mathrm{x}$ & & $\mathrm{H}$ & & & $\mathrm{x}$ & 15 \\
\hline-889 & $19-4-40$ & $\mathrm{P}$ & 80 & 3 & $0^{*}$ & 32 & 51 & W & & & $\mathrm{x}$ & Sm. & $\mathrm{x}$ & & & 83 \\
\hline-894 & $19-4-52$ & A & & 81 & $\mathrm{~S}$ & & 81 & W & & & $\mathrm{x}$ & $\mathrm{H}$ & & $\mathrm{x}$ & & 81 \\
\hline-899 & $19-4-88$ & A & & 73 & $\mathrm{~S}$ & & 73 & B & & $\mathrm{x}$ & & $\mathrm{Sm}$. & & $\mathrm{x}$ & & 73 \\
\hline-904 & $19-4-89$ & $\mathrm{P}$ & 66 & 22 & S & & 88 & W & & & $\mathrm{x}$ & $\mathrm{H}$ & & & $\mathrm{x}$ & 88 \\
\hline
\end{tabular}

(Continued)

$A=$ Ligule absent $O=$ Open Panicle $B=$ Black $H=$ Hairy

$\mathrm{P} \equiv$ Ligule Present $\mathrm{S} \equiv$ Side Panicle $\mathrm{W}=$ White Sm. $=$ Smooth 
TABLE 23.-Concluded.

\begin{tabular}{|c|c|c|c|c|c|c|c|c|c|c|c|c|c|c|}
\hline \multirow{3}{*}{$\begin{array}{c}1925 \\
\text { Row } \\
\text { Number }\end{array}$} & \multirow{3}{*}{ N. H. N. } & \multicolumn{3}{|c|}{ Ligule } & \multicolumn{3}{|c|}{ Panicle Type } & \multicolumn{4}{|c|}{ Grain Color } & \multicolumn{3}{|c|}{ Rachilla Pubesce } \\
\hline & & \multirow{2}{*}{$\begin{array}{l}\ddot{\Xi} \\
\frac{\pi}{2} \\
\text { L }\end{array}$} & \multicolumn{2}{|c|}{ 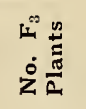 } & \multirow{2}{*}{$\frac{\ddot{\Xi}}{a}$} & \multicolumn{2}{|c|}{ 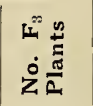 } & \multirow{2}{*}{$\begin{array}{l}\vec{E} \\
\frac{5}{2} \\
L^{\prime 2}\end{array}$} & \multicolumn{3}{|c|}{$\underset{\text { Families }}{\mathbf{F}_{3}}$} & \multirow{2}{*}{ 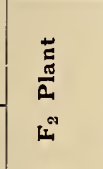 } & \multicolumn{2}{|c|}{$\begin{array}{c}\mathbf{F}_{3} \\
\text { Famili }\end{array}$} \\
\hline & & & $\mathbf{P}$ & A & & o & $\mathbf{s}$ & & $\infty$ & $\begin{array}{l}\dot{8} \\
\dot{0} \\
\tilde{n}\end{array}$ & 3 & & ह่ & $\dot{\infty}$ \\
\hline $911-915$ & $19-4-94$ & $\mathrm{P}$ & 79 & & $\mathrm{O}$ & 58 & 21 & B & & $\mathrm{x}$ & & $\mathrm{H}$ & & \\
\hline $916-920$ & $19-5-13$ & A & 61 & 24 & $\mathrm{~S}$ & & 85 & W & & & $x$ & Sm. & & $x$ \\
\hline $921-925$ & $19-5-15$ & $P$ & 63 & 22 & $\mathrm{~S}$ & & 85 & B & & $\mathrm{x}$ & & $\mathrm{Sm}$ & & \\
\hline $926-930$ & $19-5-16$ & $\mathrm{P}$ & 78 & & $\mathrm{O}$ & 59 & 19 & W & & & $\mathrm{x}$ & $\mathrm{H}$ & & \\
\hline $931-935$ & $19-5-17$ & $\mathrm{P}$ & 87 & & $\mathrm{O}$ & 70 & 17 & B & $\mathrm{x}$ & & & $\mathrm{H}$ & & \\
\hline $943-946$ & $19-5-32$ & $P$ & 58 & 21 & $\mathrm{~S}$ & & 79 & B & & $\bar{x}$ & & Sm. & & $\bar{x}$ \\
\hline $947-951$ & $19-5-33$ & $\mathrm{P}$ & 66 & 17 & $\mathrm{~S}$ & & 83 & B & & $\mathrm{x}$ & & $\mathrm{H}$ & & \\
\hline $952-956$ & $19-5-35$ & $\mathrm{P}$ & 90 & & $\mathrm{O}$ & 90 & & W & & & $\mathrm{x}$ & $\mathrm{H}$ & & \\
\hline $957-961$ & $19-5-36$ & $\mathrm{P}$ & 64 & 21 & $\mathrm{~S}$ & & 85 & W & & & $\mathrm{x}$ & Sm. & $\mathrm{x}$ & \\
\hline $962-966$ & $19-5-38$ & A & & 75 & $\mathrm{~S}$ & & 75 & $B$ & $\mathrm{x}$ & & & Sm. & & $\mathrm{x}$ \\
\hline $973-977$ & $|9-6-2|$ & A & & 86 & $\mathrm{~S}$ & & 86 & B & $\mathrm{x}$ & & & $\mathrm{H}$ & & \\
\hline $978-982$ & $19-6-27$ & $\mathrm{P}$ & & 87 & $\mathrm{~S}$ & & 87 & B & $\mathrm{x}$ & & & Sm. & $\mathrm{x}$ & \\
\hline $983-987$ & $19-6-32$ & $\mathrm{P}$ & 54 & 22 & $\mathrm{~S}$ & & 76 & B & & $\mathbf{x}$ & & $\mathrm{H}$ & & $x$ \\
\hline $988-992$ & $19-6-33$ & $\mathrm{P}$ & 79 & & $\mathrm{O}$ & 79 & & B & & $\mathrm{x}$ & & $\mathrm{H}$ & & $x$ \\
\hline $993-997$ & $19-6-40$ & $\mathrm{P}$ & 75 & 8 & $\mathrm{O}$ & 50 & 33 & W & & & $\mathrm{x}$ & Sm. & & $\mathrm{x}$ \\
\hline $998-1002$ & $19-6-51$ & $\mathrm{P}$ & 69 & 5 & $\mathrm{O}$ & 45 & 29 & B & & $\mathrm{x}$ & & $\mathrm{Sm}$ & & $\mathrm{x}$ \\
\hline
\end{tabular}

$\mathrm{A}=$ Ligule absent $\mathrm{O}=$ Open Panicle $\mathrm{B}=$ Black $\mathrm{H}=$ Hairy

$\stackrel{A}{\mathrm{~A}} \equiv$ Ligule Present $\mathrm{S} \equiv$ Side Panicle $\mathrm{W}=$ White $\mathrm{Sm}$. $=$ Smooth Seg. = Segregating 
LE 24. - Breeding behavior for ligule and panicle type of single row $F_{3}$ progenies grown from $1924 \mathrm{~F}_{2}$ plants.

\begin{tabular}{|c|c|c|c|c|c|c|c|c|}
\hline \multirow{3}{*}{$\begin{array}{l}25 \\
\text { ow } \\
\text { Vaber }\end{array}$} & \multirow{3}{*}{ N. H. N. } & \multicolumn{3}{|c|}{ Ligule } & \multicolumn{3}{|c|}{ Panicle Type } & \multirow{3}{*}{$\begin{array}{l}\dot{z} \\
\dot{z} \\
\dot{0} \\
\stackrel{-}{\circ}\end{array}$} \\
\hline & & \multirow{2}{*}{$\begin{array}{l}\vec{a} \\
\vec{a} \\
L^{\text {aN }}\end{array}$} & \multicolumn{2}{|c|}{ No. $F_{3}$ Plants } & \multirow{2}{*}{ 苛 } & \multicolumn{2}{|c|}{ No. $F_{3}$ Plants } & \\
\hline & & & $\mathbf{P}$ & $\mathbf{A}$ & & o & $\mathbf{s}$ & \\
\hline 87 & $18-1-22$ & $\mathrm{P}$ & 18 & & $\mathrm{~S}$ & & 18 & 18 \\
\hline 88 & $18-1-33$ & $\mathrm{P}$ & 14 & 3 & $\mathrm{~S}$ & 9 & 8 & 17 \\
\hline 89 & $18-1-41$ & $\mathrm{P}$ & 15 & 5 & $\mathrm{~S}$ & & 20 & 20 \\
\hline 90 & $18-4-18$ & $\mathrm{P}$ & 15 & 5 & $\mathrm{~S}$ & & 20 & 20 \\
\hline 91 & $18-4-21$ & $\mathrm{P}$ & 11 & 3 & $\mathrm{~S}$ & & 14 & 14 \\
\hline 92 & $18-4-65$ & $\mathrm{P}$ & 14 & 5 & $\mathrm{~S}$ & & 19 & 19 \\
\hline 93 & $18-6-163$ & A & & 14 & $\mathrm{~S}$ & & 14 & 14 \\
\hline 194 & $19-3-17$ & $\mathrm{~A}$ & & 16 & $\mathrm{~S}$ & & 16 & 16 \\
\hline 95 & $19-4-47$ & A & & 17 & $\mathrm{~S}$ & & 17 & 17 \\
\hline 196 & $19-4-92$ & A & & 19 & $\mathrm{~S}$ & & 19 & 19 \\
\hline 197 & $19-5-25$ & $\mathrm{~A}$ & & 17 & $\mathrm{~S}$ & & 17 & 17 \\
\hline 198 & $19-6-22$ & $\mathrm{P}$ & 9 & 7 & $\mathrm{~S}$ & & 16 & 16 \\
\hline 199 & $19-6-41$ & $\mathrm{P}$ & 13 & 3 & $\mathrm{~S}$ & & 16 & 16 \\
\hline 00 & $19-6-43$ & $\mathrm{P}$ & 17 & & $\mathrm{~S}$ & & 17 & 17 \\
\hline 01 & $19-6-53$ & $\mathrm{P}$ & 17 & 1 & $\mathrm{~S}$ & & 18 & 18 \\
\hline
\end{tabular}


TABLE 25.- Breeding behavior for ligule and panicle type of single rou progenies grown from $1923 \mathrm{~F}_{2}$ plants.

\begin{tabular}{|c|c|c|c|c|c|c|c|c|}
\hline \multirow{3}{*}{$\begin{array}{c}1925 \\
\text { Row } \\
\text { Number }\end{array}$} & \multirow{3}{*}{ N. H. N. } & \multicolumn{3}{|c|}{ Ligule } & \multicolumn{3}{|c|}{ Panicle Type } & \multirow{3}{*}{ 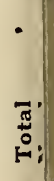 } \\
\hline & & \multirow{2}{*}{$\begin{array}{l}\dot{\vec{E}} \\
\overrightarrow{0} \\
\text { से }\end{array}$} & \multicolumn{2}{|c|}{ No. $F_{3}$ Plants } & \multirow{2}{*}{ 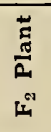 } & \multicolumn{2}{|c|}{ No $F_{3}$ Plants } & \\
\hline & & & $\mathbf{P}$ & $\mathbf{A}$ & & 0 & s & \\
\hline 1009 & $18-1-1$ & $P$ & 16 & & $\mathrm{O}$ & 16 & & it \\
\hline 1010 & $18-1-3$ & $P$ & 12 & 3 & $\mathrm{~S}$ & & 15 & $1:$ \\
\hline 1011 & $18-1-8$ & $\mathrm{P}$ & 9 & 4 & $\mathrm{~S}$ & & 13 & 13 \\
\hline 1012 & $18-1-17$ & $\mathrm{~A}$ & 7 & 4 & $S$ & & 11 & 11 \\
\hline 1013 & $18-1-19$ & $\mathrm{P}$ & 8 & 5 & $\mathrm{~S}$ & & 13 & 13 \\
\hline 1014 & $18-2-8$ & $\mathrm{P}$ & 13 & & $\mathrm{O}$ & 13 & & 13 \\
\hline 1015 & $18-2-11$ & $\mathrm{P}$ & 5 & 5 & $\mathrm{~S}$ & & 10 & 10 \\
\hline 1016 & $18-2-12$ & A & & 6 & $\mathbf{S}$ & & 6 & 6 \\
\hline 1017 & $18-3-1$ & $\mathrm{P}$ & 13 & 3 & $\mathrm{~S}$ & & 16 & 16 \\
\hline 1018 & $18-3-4$ & $\mathrm{P}$ & 13 & 1 & $\mathrm{O}$ & 10 & 4 & 14 \\
\hline 1019 & $18-3-10$ & $\mathbf{P}$ & 10 & 5 & $\mathrm{~s}$ & & 15 & 15 \\
\hline 1020 & $18-3-18$ & A & & 13 & $\mathrm{~S}$ & & 13 & 13 \\
\hline 1021 & $18-3-21$ & $\mathrm{P}$ & 7 & 2 & $\mathrm{~S}$ & & 9 & 9 \\
\hline 1022 & $18-3-25$ & $\mathrm{P}$ & 8 & 1 & $\mathrm{~S}$ & & 9 & 9 \\
\hline 1023 & $18-4-9$ & A & & 13 & $S$ & & 13 & 13 \\
\hline 1024 & $18-5-2$ & $\mathrm{~A}$ & & 11 & $\mathrm{~s}$ & & 11 & 11 \\
\hline 1025 & $18-5-3$ & $\mathrm{P}$ & 13 & & $S$ & & 13 & 13 \\
\hline 1026 & $18-5-8$ & $P$ & 18 & & 0 & 18 & & 18 \\
\hline 1027 & $18-5-24$ & $\mathrm{P}$ & 12 & 1 & $\mathrm{~S}$ & & 13 & 13 \\
\hline 1028 & $18-6-8$ & $\mathrm{~A}$ & & 14 & $\mathrm{~s}$ & & 14 & 14 \\
\hline 1029 & $18-6-11$ & $\mathrm{P}$ & 5 & 2 & $\mathrm{~S}$ & & 7 & 7 \\
\hline 1030 & $18-6-13$ & $\mathrm{P}$ & 9 & 5 & $\mathrm{~S}$ & & 14 & 14 \\
\hline 1031 & $18-6-16$ & $\mathrm{P}$ & 12 & 3 & $\mathrm{~s}$ & & 15 & 15 \\
\hline 1032 & $18-6-4$ & $\mathrm{P}$ & 5 & 7 & $\mathrm{~s}$ & & 12 & 12 \\
\hline 1033 & $18-6-23$ & A & & 16 & $\mathrm{~S}$ & & 16 & 16 \\
\hline
\end{tabular}


BLE 25.-Continued.

\begin{tabular}{|c|c|c|c|c|c|c|c|c|}
\hline \multirow{3}{*}{$\begin{array}{l}1925 \\
\text { Row } \\
\text { umber }\end{array}$} & \multirow{3}{*}{ N. H. N. } & \multicolumn{3}{|c|}{ Ligule } & \multicolumn{3}{|c|}{ Panicle Type } & \multirow{3}{*}{ 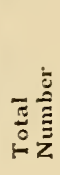 } \\
\hline & & \multirow{2}{*}{$\begin{array}{l}\ddot{\Xi} \\
\ddot{\Xi} \\
\ddot{E}\end{array}$} & \multicolumn{2}{|c|}{ No. $F_{3}$ Plants } & \multirow{2}{*}{$\begin{array}{l}\vec{\Xi} \\
\frac{\vec{E}}{2} \\
\dot{u}^{\prime}\end{array}$} & \multicolumn{2}{|c|}{ No. $F_{3}$ Plants } & \\
\hline & & & $P$ & $A$ & & 0 & $\mathrm{~s}$ & \\
\hline 1034 & $18-6-29$ & $P$ & 9 & 4 & $\mathrm{~S}$ & & 13 & 13 \\
\hline 1041 & $18-6-33$ & $\mathrm{P}$ & 8 & 6 & $\mathrm{~S}$ & & 14 & 14 \\
\hline 1042 & $18-6-38$ & $\mathrm{P}$ & 11 & 3 & $\mathrm{~S}$ & & 14 & 14 \\
\hline 1043 & $18-6-42$ & $\mathrm{P}$ & 9 & 4 & $\mathrm{~S}$ & & 13 & 13 \\
\hline 1044 & $18-6-48$ & $\mathrm{P}$ & 15 & & $\mathrm{~s}$ & 8 & 7 & 15 \\
\hline 1045 & $18-6-51$ & $\mathrm{P}$ & 9 & 5 & $\mathrm{~s}$ & & 14 & 14 \\
\hline 1046 & $18-6-58$ & $P$ & 11 & & $\mathrm{O}$ & 7 & 4 & 11 \\
\hline 1047 & $18-6-60$ & $\mathrm{P}$ & 12 & & $\mathrm{O}$ & 5 & 7 & 12 \\
\hline 1048 & $18-6-78$ & $\mathrm{~A}$ & & 13 & $\mathrm{~S}$ & & 13 & 13 \\
\hline 1049 & $18-6-85$ & $\mathrm{P}$ & 11 & & $\mathrm{O}$ & 5 & 6 & 11 \\
\hline 1050 & $18-6-86$ & $\mathrm{P}$ & 13 & & $\mathrm{~S}$ & & 13 & 13 \\
\hline 1051 & $18-6-89$ & $\mathrm{P}$ & 15 & 1 & $\mathrm{O}$ & 9 & 7 & 16 \\
\hline 1052 & $18-6-92$ & $\mathrm{~A}$ & & 13 & $\mathrm{~S}$ & & 13 & 13 \\
\hline 1053 & $18-6-94$ & $P$ & 12 & 3 & $\mathrm{~s}$ & & 15 & 15 \\
\hline 1054 & $18-6-102$ & $\mathrm{P}$ & 12 & 4 & $\mathrm{~S}$ & & 16 & 16 \\
\hline 1055 & $18-6-103$ & A & & 13 & $\mathrm{~s}$ & & 13 & 13 \\
\hline 1056 & $18-6-106$ & $\mathrm{P}$ & 13 & & $\mathrm{O}$ & 7 & 6 & 13 \\
\hline 1057 & $18-6-108$ & $\mathrm{P}$ & 13 & & $\mathrm{~S}$ & & 13 & 13 \\
\hline 1058 & $18-6-109$ & $\mathrm{P}$ & 10 & 7 & $\mathrm{~S}$ & & 17 & 17 \\
\hline 1059 & $18-6-111$ & $\mathrm{P}$ & 12 & & 0 & 5 & 7 & 12 \\
\hline 1060 & $18-6-113$ & $\mathrm{P}$ & 16 & & 0 & 11 & 5 & 16 \\
\hline 1067 & $19-1-1$ & $P$ & 14 & 6 & $\mathrm{~S}$ & & 20 & 20 \\
\hline 1068 & $19-1-2$ & A & & 16 & $\mathrm{~S}$ & & 16 & 16 \\
\hline$: 069$ & $19-1-20$ & $\mathrm{~A}$ & & 14 & $S$ & & 14 & 14 \\
\hline 1070 & $19-2-5$ & A & & 16 & $\mathrm{~S}$ & & 16 & 16 \\
\hline 1071 & $19-3-4$ & A & & 17 & $\mathrm{~s}$ & & 17 & 17 \\
\hline
\end{tabular}


TABLE 25.- Concluded.

\begin{tabular}{|c|c|c|c|c|c|c|c|c|}
\hline \multirow{3}{*}{$\begin{array}{c}1925 \\
\text { Row } \\
\text { Number }\end{array}$} & \multirow{3}{*}{ N. H. N. } & \multicolumn{3}{|c|}{ Ligule } & \multicolumn{3}{|c|}{ Panicle Type } & \multirow{3}{*}{ 풀 } \\
\hline & & \multirow{2}{*}{ 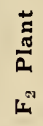 } & \multicolumn{2}{|c|}{ No. $F_{3}$ Plants } & \multirow{2}{*}{ 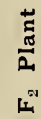 } & \multicolumn{2}{|c|}{ No. $F_{3}$ Plants } & \\
\hline & & & $\mathbf{P}$ & $\mathbf{A}$ & & o & $\mathbf{S}$ & \\
\hline 1072 & $19-3-5$ & $\mathrm{P}$ & 8 & 3 & S & & 11 & 1 \\
\hline 1073 & $19-4-1$ & $\mathrm{P}$ & 13 & 5 & $\mathrm{~S}$ & & 18 & 1 \\
\hline 1074 & $19-4-5$ & $\mathrm{P}$ & 9 & 4 & $S$ & & 13 & 1 \\
\hline 1075 & $19-5-2$ & A & & 10 & $\mathrm{~S}$ & & 10 & 1 \\
\hline 1076 & $19-5-4$ & $\mathrm{P}$ & 15 & 2 & $S$ & & 17 & 1 \\
\hline 1077 & $19-6-2$ & $\mathbf{P}$ & 13 & 6 & S & & 19 & 1 \\
\hline 1078 & $19-6-12$ & $\mathbf{P}$ & 15 & 2 & S & & 17 & 1: \\
\hline 1079 & $19-6-13$ & $\mathrm{P}$ & 13 & 2 & $S$ & & 15 & 1 \\
\hline 1080 & $19-6-14$ & $\mathrm{P}$ & 11 & 4 & $\mathrm{~S}$ & 7 & 8 & 1 \\
\hline
\end{tabular}





\section{HECKMAN}

BINDERY INC.

\section{JUNE 99}

Bound -To-Please N. MANCHESTEA 


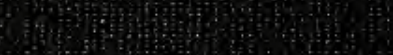
4. (3)

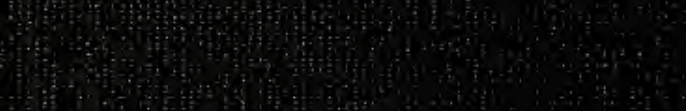

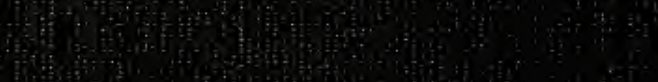
Pan int

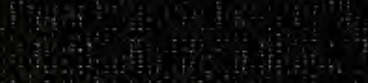

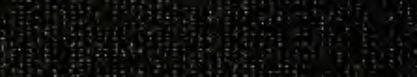
\#) (m) (3) 